NBER WORKING PAPER SERIES

\title{
EMPIRICAL EVIDENCE ON THE AGGREGATE EFFECTS OF ANTICIPATED AND UNANTICIPATED U.S. TAX POLICY SHOCKS
}

\author{
Karel Mertens \\ Morten Ravn \\ Working Paper 16289 \\ http://www.nber.org/papers/w16289 \\ NATIONAL BUREAU OF ECONOMIC RESEARCH \\ 1050 Massachusetts Avenue \\ Cambridge, MA 02138 \\ August 2010
}

Parts of this paper were earlier circulated under the title "The Aggregate Effects of Anticipated and Unanticipated U.S. Tax Policy Shocks: Theory and Empirical Evidence". We are grateful for comments received from Robert Barro, Peter Claeys, Stephen Coate, Bob Driskill, Martin Eichenbaum, Carlo Favero, Jordi Galì, Mark Gertler, Eric Leeper, Roberto Perotti, Juan Rubio-Ramirez, Raf Wouters, and from seminar participants at the TAPES conference, 2010, SED 2008, ESSIM 2008, the Belgian National Bank, Bocconi University, Cornell University, Norges Bank, Penn State University, University of Amsterdam, UC Davis, University College London, Universite' Catholique de Louvain, University of Southampton, University of Warwick and at the Federal Reserve Banks of Chicago and San Francisco. We also thank Andres Dallal for superb research assistance. The responsibility for any errors is entirely ours. The views expressed herein are those of the authors and do not necessarily reflect the views of the National Bureau of Economic Research.

NBER working papers are circulated for discussion and comment purposes. They have not been peerreviewed or been subject to the review by the NBER Board of Directors that accompanies official NBER publications.

(C) 2010 by Karel Mertens and Morten Ravn. All rights reserved. Short sections of text, not to exceed two paragraphs, may be quoted without explicit permission provided that full credit, including @ notice, is given to the source. 
Empirical Evidence on the Aggregate Effects of Anticipated and Unanticipated U.S. Tax Policy Shocks

Karel Mertens and Morten Ravn

NBER Working Paper No. 16289

August 2010

JEL No. E20,E32,E62,H30

\begin{abstract}
We provide empirical evidence on the dynamics effects of tax liability changes in the United States. We distinguish between surprise and anticipated tax changes using a timing-convention. We document that pre-announced but not yet implemented tax cuts give rise to contractions in output, investment and hours worked while real wages increase. In contrast, there are no significant anticipation effects on aggregate consumption. Implemented tax cuts, regardless of their timing, have expansionary and persistent effects on output, consumption, investment, hours worked and real wages. Results are shown to be very robust. We argue that tax shocks are empirically important impulses to the U.S. business cycle and that anticipation effects have been important during several business cycle episodes.
\end{abstract}

\author{
Karel Mertens \\ Cornell University \\ km426@ cornell.edu \\ Morten Ravn \\ Department of Economics \\ University College London \\ London WC1E 6BT \\ UK \\ morten.ravn@eui.eu
}




\section{Introduction}

This paper estimates the dynamic macroeconomic effects of tax changes in the United States for the post World War II period. We take into account the timing of tax changes by introducing a distinction between anticipated and unanticipated changes in taxes. According to economic theory, agents base their decision rules upon their current information about variables relevant for the decision problem. Unanticipated changes in taxes affect behavior when the tax changes are implemented, while anticipated changes in taxes may affect the economy ahead of their introduction. The idea that anticipated policy shocks impact on the economy prior to their implementation has been explored extensively in the literature on fiscal policy, see e.g. Hall, 1971, Auerbach, 1989, Yang, 2005, and House and Shapiro, 2006, for the case of tax shocks, or Blanchard, 1981, Taylor, 1993, and Ramey, 2008, for the case of government spending shocks. Yet, there is little if any direct empirical evidence that anticipation effects are empirically relevant. This paper provides such evidence for the U.S. economy. Moreover, by explicitly taking the timing of tax changes into account, we are better able to estimate the impact of implemented tax changes than preexisting studies.

Our analysis is based upon a narrative account measurement of tax changes. Specifically, we adopt the narrative account of post World War II legislated federal U.S. tax bills provided by Romer and Romer (2007, 2008). We focus upon those tax changes that Romer and Romer (2008) classify as exogenous because they were introduced either for ideological reasons or because they were motivated by "inherited deficit concerns" (as opposed to deficits caused by current spending). There are 70 such tax liability changes that derive from 35 different federal tax policy acts. The distinction between anticipated and unanticipated tax shocks is accomplished by introducing a timing convention. We define for each tax act the announcement date and the implementation date of the tax liability changes. The announcement date is assumed to correspond to the date at which the policy intervention became law while the implementation date is defined as the date at which the tax liability changes were to be implemented according to the tax acts. When these dates are no longer than 90 days apart, we classify the corresponding tax liability change as an unanticipated tax shock, while anticipated tax shocks are those changes in taxes for which the two dates differ by more than 90 days. Based on this measurement, 37 out of the 70 tax liability changes are categorized as anticipated and the median anticipation horizon amongst these tax shocks is 6 quarters. 
The use of this timing convention provides a methodological innovation to the problem of estimating anticipation effects in the macroeconomic literature on fiscal policy. Alternatively, Blanchard and Perotti (2002) suggest the use of an instrumental variables estimator. These authors identify fiscal shocks by exploiting the existence of decision lags assuming that fiscal policy variables do not adjust within a quarter to other unanticipated shocks but point out that decision lags need to exceed implementation lags if there are pre-announced tax changes. Since the median implementation lag in our data is 6 quarters, this approach would therefore have to rely on unrealistically long reaction lags when estimating the dynamic impact of unanticipated and anticipated tax shocks. ${ }^{1}$

We estimate the impact of the tax shocks on main macroeconomic aggregates using a VAR approach treating the tax liability changes as exogenous shocks. This approach is akin to analyses that have examined the impact of government spending shocks using the narrative approach (e.g. Ramey and Shapiro, 1998, Burnside, Eichenbaum and Fisher, 2004, or Ramey, 2008) with the added feature that we distinguish between anticipated and unanticipated fiscal shocks. The key findings are:

- An unanticipated tax cut gives rise to significant increases in output, consumption, and investment which peak around 2.5 years after the introduction of the tax cut. The largest response relates to investment that after a 1 percent tax cut increases by approximately 10 percent at peak. Hours worked also increases but only gradually over time. Real wages rise persistently.

- An anticipated tax cut is associated with pre-implementation drops in output and investment while consumption remains roughly constant during the pre-implementation period. Once the tax change is implemented, it is associated with a stimulating effect on the economy. There is also a significant pre-implementation drop in hours worked, while real wages increase during the pre-implementation period.

- Unanticipated and anticipated tax shocks have contributed importantly to the U.S. business cycle. In particular, the anticipation effects associated with the Social Security Amendments

\footnotetext{
${ }^{1}$ Mountford and Uhlig (2009) estimate the impact of pre-announced fiscal policy shocks using a structural VAR approach where identification is obtained by imposing sign restrictions. They do not show, however, whether anticipation effects have been important quantitively for fluctuations in the U.S. economy. Mertens and Ravn (2010b) propose an alternative structural VAR estimator which applies Blaschke matrices to correct for anticipation effects.
} 
of 1977 and the Economic Recovery Tax Act of 1981 explain a significant proportion of the 1981-82 recession and the mid-1980's boom in the U.S. The Bush tax initiatives in the early 2000's also had important anticipation effects. Tax shocks account for around 20-25 percent of the volatility of output at business cycle frequencies.

In contrast to preexisting studies, our results provide direct empirical evidence on the importance of anticipation effects. A number of papers have examined the consumption response to pre-announced changes in personal taxes. Poterba (1988) tests whether aggregate U.S. consumption reacts to announcements of future tax changes and fails to find robust evidence in favor of this hypothesis. $^{2}$ Heim (2007) studies data from the Consumer Expenditure Survey (CEX) and tests for announcement effects of state tax rebates. He finds no significant household consumption response to rebate announcements. Parker (1999) and Souleles $(1999,2002)$ also study CEX data and test whether household consumption responds to actual changes in taxes when these were known in advance of their implementation. ${ }^{3}$ They find that consumption plans adjust only when tax changes are implemented. Our results regarding the impact of taxes on consumption agree with these studies but indicate that other key macroeconomic variables do display significant anticipation effects. This is important because the existing evidence on pre-announcement effects on consumption has been interpreted in terms of lack of foresight on the part of households and/or binding liquidity constraints. We argue that the drop in hours worked and the increase in investment in response to announcements of future tax cuts indicate forward looking behavior and are hard to reconcile with large shares of liquidity constrained agents.

We carry out an extensive robustness analysis. We first examine reliability of the timing-based measurement of anticipated tax shocks. Specifically, we allow leads of surprise tax changes to affect the vector of observables which should be the case if the public had good knowledge of tax changes prior to them becoming law. We find little evidence to indicate that surprise tax changes systematically have any impact before their implementation which supports the timing-based measurement

\footnotetext{
${ }^{2}$ Poterba (1988) identifies five such episodes: February 1964, June 1968, March 1975, August 1981, and August 1986.

${ }^{3}$ Parker (1999) examines the impact of Social Security changes during the 1980's while Souleles (2002) investigates the Reagan tax cut of the early 1980's.
} 
of anticipated tax shocks.

Secondly, we investigate whether our results are driven by endogeneity of the tax shocks. We examine the predictability of the tax changes using an ordered probit model distinguishing between surprise and anticipated tax changes and taking into account the motivation for their introduction. We cannot reject exogeneity of tax changes that were introduced for ideological reasons. The results for deficit driven tax changes are less clear with some mild (but not very strong) evidence indicating predictability of announcements of future deficit driven tax liability changes. Although the evidence on endogeneity is weak, we repeat our analysis eliminating all deficit driven tax changes from the data but find that this does not overturn any of the main results. We also investigate whether the estimation results hinge critically on particular tax laws. We remove three particularly large tax interventions the Reagan tax cut being the most prominent. We show that the results are robust to removing any of these three tax acts.

Finally, we ask whether our results are contaminated by lack of control for monetary policy and for fiscal spending which might be an important issue in small samples. Our results become perhaps even stronger when we control for monetary policy shocks or for government spending shocks. Moreover, our finding that the anticipation effects associated with the Reagan tax cut were partially responsible for the early 1980's recession in the US holds true even when we control for monetary policy shocks.

The remainder of the paper is structured as follows. Section 2 describes our estimation approach and discusses the tax data. Section 3 contains the main results regarding the dynamic effects of tax shocks. A substantial robustness analysis is discussed in Section 4. Section 5 contains our analysis of the role of tax shocks for US business cycles. Finally, Section 6 concludes and summarizes.

\section{Estimation Approach}

In this section we discuss how we measure tax shocks and our approach to the estimation of their impact on macroeconomic aggregates.

\section{$2.1 \quad$ Identification}

Key to any estimation of the impact of fiscal policy shocks is the identification strategy. Recent contributions to the fiscal policy literature have adopted either structural VAR approaches or have 
relied upon narrative approaches. We follow the second identification strategy. The key advantage of the narrative approach is that it allows us to make a distinction between anticipated and unanticipated tax shocks based on timing assumptions and therefore, at least partially, to control for ex-ante available information about future changes in taxes that is usually ignored in standard VAR based methods. ${ }^{4}$ Specifically, we make use of Romer and Romer's (2007) (updated in Romer and Romer, 2008) narrative account of U.S. federal tax liability changes. Based on official government documents, presidential speeches, and Congressional documents, these authors identify 51 significant legislated federal tax acts in the period 1947-2006 and a total of 110 separate changes in tax liabilities. This account is therefore much richer than the standard narrative account of fiscal spending (Ramey and Shapiro, 1998).

We focus on the tax liability changes that Romer and Romer (2007) classify as exogenous since "(t)he changes were not motivated by current or projected economic conditions" (Romer and Romer, 2007, p.3). This includes tax liability changes that Romer and Romer (2007) classify as either "exogenous due to long-term growth objectives" or exogenous due to "deficit concerns". The former of these are tax changes that were introduced with no explicit concerns about the current state of the economy while the latter are tax changes introduced to address inherited budget deficits. Our benchmark estimates of the impact of these tax shocks includes all of these tax liability changes but we later examine in some detail whether there are signs of endogeneity of the tax liability changes. This selection leaves us with 70 tax liability changes deriving from 35 different federal tax policy acts listed in Table A.1.

\subsection{Distinguishing Between Anticipated and Unanticipated Tax Shocks}

We adopt a timing based distinction between unanticipated and anticipated tax shocks. For each tax liability change we define two dates, the announcement date and the implementation date. We assume that the announcement date corresponds to the date at which the tax legislation became law, i.e. when it was signed by the President. The implementation date is instead the date at which,

\footnotetext{
${ }^{4}$ Blanchard and Perotti (2002) point out that allowing for anticipated shocks in a structural VAR framework where identification of fiscal policy shocks rests upon decision lags implies the need for using instrumental variables estimators and assuming decision lags that exceed announcement lags.
} 
according to each tax legislation, the tax liability changes were to be introduced. ${ }^{5}$ We refer to the difference between these two dates as the implementation lag.

Figure 1 illustrates the histogram of the implementation lag (in days) in the data. It is evident that the histogram of the implementation lag is twin peaked with the peaks occurring at 0-30 days and at more than 151 days. Only 18 of the 70 tax liability changes have implementation lags in the 30-150 days interval. In our benchmark analysis we define a tax liability change as anticipated if the implementation lag exceeds 90 days which strikes a balance between robustness of the classification to the timing within a quarter and the ability to measure anticipation effects. The twin peaked nature of the frequency of the implementation lag implies that minor changes in the width of the window have little impact.

Based on this definition, 36 out of the 70 of the tax liability changes are anticipated while 34 tax liability changes are defined as surprise tax shocks. The resulting tax shocks are illustrated in Figure 2 in percentages of annual current price GDP. The top panel shows the unanticipated shocks, the middle panel shows the anticipated shocks dated by the quarter of implementation, and the bottom panel reports the anticipation horizon of the anticipated tax shocks (truncated at 4 years).

As is evident, the tax liability changes are quite frequent and some of them are quite large. The Reagan tax initiative, the Economic Recovery Tax Act of 1981 (ERTA 1981 from now on), signed by Reagan in August 1981, contained a substantial amount of pre-announced tax changes. It consisted of five separate changes in tax liabilities due in 1981:3, 1981:4, 1982:1, 1983:1, and 1984:1. The first two tax changes are defined as surprise changes according to our taxonomy while the last three initiatives are defined as anticipated policy changes. The change in tax liabilities of these latter three anticipated changes corresponds to approximately 4.5 percent of annual GDP. This sequence of tax cuts as a whole constitutes by far the largest anticipated tax changes in the sample that we study.

The median implementation lag in the data is 6 quarters while the longest implementation lag is associated with the Social Security Amendments of 1983 signed by Reagan in April 1983 which had tax liability changes being introduced as far out in the future as 1990. Most other pre-announced

\footnotetext{
${ }^{5}$ When the tax bill is advanced by the President, the bill becomes law when passed by the Congress. This date may occur slightly earlier than the bill being signed by the President. However, given that we introduce a 90 day minimum anticipation horizon, this detail should not affect our results.
} 
tax changes, however, had implementation lags close to the median lag (only 5 tax changes have anticipation lags longer than 4 years).

The timing based distinction between surprise and anticipated changes in taxes is parallel to the approach taken in microeconometric estimates of the impact of pre-announced tax changes on household consumption (Heim, 2007, Parker, 1999, Souleles, 1999, 2002) and in Poterba's classic (1988) study of the aggregate consumption response to tax announcements. One might consider taking into account promises made during election campaigns, lags in the democratic process of passing tax legislations, etc. to arrive at more sophisticated measurements of the arrival of information about future tax interventions. The advantage of the approach taken here is that the measurement is consistent across all tax liability changes and it is easily reproducible. Nevertheless, in the robustness analysis we take a closer look at the plausibility of this assumption.

Another issue relates to the timing of the announcements of anticipated tax shocks. Suppose that the announcements were systematically related to the state of the business cycle. In this case, while the motivation for the tax changes may not be related to current economic conditions, the timing of their introduction may reflect concerns about the state of the economy. To check this, we computed the average number of quarters between announcements of future tax changes and the closest NBER business cycle turning point. This statistic is 5.7 quarters in the data. Assuming that tax announcements are random so that they occur with the same probability at all dates gives an expected value of this statistic of 5.8 quarters. Thus, we find no signs of a systematic relationship between announcements of future tax changes and business cycle turning points.

\subsection{Measurement of Tax Shocks}

We measure the size of surprise tax liability changes, denoted as $\tau_{t}^{u}$, as the implied dollar change in tax liabilities in percent of current price GDP at the implementation date. This tax measure converts the tax liability change into an average tax rate. It would potentially be interesting to disaggregate this measure into changes in specific taxes but we concentrate on the coarser measure since it gives us a rich amount of data to examine.

Anticipated tax changes are distinguished by size, the announcement date, and by the anticipation

horizon. Let $s_{t}^{a, i}$ denote tax liability changes that were signed by the President at date $t$ and had 
an anticipation horizon of i quarters measured as a percentage of GDP at the implementation date. Ideally, we would like to allow for differential effects of tax liabilities that had different anticipation horizons but this is infeasible due to the loss of degrees of freedom implied by the large number of tax shocks that needs to be included. To see this, note that adopting this approach implies that the information set at date $t$ must include the vector of anticipated tax shocks $\left[s_{t}^{a, i=1, . . M}, s_{t-1}^{a, i=2, . ., M}, s_{t-M}^{a, M}\right]$ where $M$ denotes the largest implementation lag in the data. For $M=20$, the largest anticipation horizon in the data, 210 parameters need to be estimating leaving only a tiny degrees of freedom available for estimating of the impact of tax changes.

To address this issue, we distinguish between anticipated tax shocks on the basis of their remaining anticipation horizon. We define the following anticipated tax shocks:

$$
\tau_{t, i}^{a}=\sum_{j=0}^{M-i} s_{t-j}^{a, i+j}
$$

Thus, $\tau_{t, i}^{a}$ measures the sum of all anticipated tax liability changes known at date $t$ to be implemented at date $t+i$. Using this definition of the anticipated tax shocks implies that the number of anticipated tax variables that enter the information set at date $t$ is equal to $M$, making estimation feasible.

\subsection{Estimating the Impact of Tax Liability Changes}

Given the estimates and classification of the tax shocks, we estimate the impact of tax shocks on the basis of impulse response functions. These impulse response functions are derived from the following regression model:

$$
X_{t}=A+B t+C(L) X_{t-1}+D(L) \tau_{t}^{u}+F(L) \tau_{t, 0}^{a}+\sum_{i=1}^{K} G_{i} \tau_{t, i}^{a}+e_{t}
$$

where $X_{t}$ is a vector of endogenous variables, $A$ and $B$ control for a constant term and a linear trend, $C(L)$ is $P$-order lag polynomial, and $D(L)$ and $F(L)$ are $(R+1)$-order lag polynomials. ${ }^{6}$ We allow the maximum anticipation horizon in equation $(2), K$, potentially to differ from the maximum implementation lag observed in the data, $M$. The anticipation effects of pre-announced tax liability changes are introduced through the terms $G_{1}-G_{K}$. Notice that, since these coefficients enter on the

\footnotetext{
${ }^{6}$ The results are robust to allowing for a break in the trend in 1973:2, see Ramey and Shapiro (1998) and Burnside, Eichenbaum and Fisher (2004). The results are also robust to first differencing the $X_{t}$ vector.
} 
tax liability changes that are part of the information set at date $t$ but not yet implemented, these terms directly measure news effects associated with anticipated tax shocks. Therefore, the empirical model allows us to trace out the dynamics of the economy from when tax changes are announced.

The regression model can be viewed as a vector autoregression for $X_{t}$, treating the tax variables as exogenous shocks. Since we do not include actual tax rates in the vector $X_{t}$, in order to allow for persistence in the tax liability changes the VAR includes moving average terms of implemented tax liability changes, $\tau_{t}^{u}$ and $\tau_{t, 0}^{a}$ (the $D(L)$ and $F(L)$ lag polynomials).

A main motivation for the formulation of the regression model is that it corresponds to an approximation to the dynamics of the observables in a DSGE model with stochastic shocks to tax rates, see Mertens and Ravn (2010a). We explain this in Appendix 2. The approximation consists of restricting $D(L)$ and $F(L)$ to be finite order polynomials (as opposed to infinite order polynomials). Mertens and Ravn (2010a) show that as long as $R$ is sufficiently high, the approximation is quite precise and that the VAR provides a very good fit of the dynamics of a DSGE model.

Our treatment of the tax shocks contrasts with the standard "dummy variable" measurement of the policy interventions usually adopted in the narrative approach, see e.g. Ramey and Shapiro (1998) or Burnside, Eichenbaum and Fisher (2004). ${ }^{7}$ The advantage of our approach is that it allows us to aggregate the evidence across different episodes of tax liability changes. This seems a sensible strategy given that we have quite a large number of tax shocks, and given that their measurement can be interpreted in terms of changes in average taxes.

We study U.S. quarterly data for the sample period 1947:1 - 2006:4. In all our experiments, the vector $X_{t}$ includes the following variables:

$$
X_{t}=\left[y_{t}, c_{t}, i_{t},\right]^{\prime}
$$

where $y_{t}$ denotes the logarithm of U.S. GDP per adult in constant (chained) prices, $c_{t}$ is the logarithm of the real per capita private sector consumption expenditure, $i_{t}$ is the logarithm of real aggregate per capita gross private sector investment (see Appendix 2 for precise definitions and data sources). We also estimate the impact of the tax shocks on hours worked and on real wages by adding these variables sequentially to the vector of observables. This strategy requires the estimation of a fewer number

\footnotetext{
${ }^{7}$ See Perotti (2007) for an insightful discussion of the narrative approach to fiscal policy.
} 
of parameters than estimating the larger dimensional VAR directly, see also Burnside, Eichenbaum and Fisher (2004). ${ }^{8}$

The VAR above assumes that the tax shocks have persistent but non-permanent effects on the vector of observables (under the condition that the lag-polynomial $C(L)$ does not contain unit roots). We also checked the results when allowing for permanent effects of the tax shocks using a VAR in first differences. The results are very similar to those that we derive with the VAR in equation (2) and are therefore not reported.

\section{Empirical Results}

We assume that $K=6$ which corresponds to the median implementation lag in the data that we study, that $R=12$, and that $P=1$ (the results are robust to assuming longer lag structures). We report the impulse response functions to a 1 percent decrease in the tax liabilities (relative to GDP) along with 68 percent non-parametric non-centered bootstrapped confidence intervals computed from 10000 replications. ${ }^{9}$ The impulse response functions are shown for a forecast horizon of 24 quarters for unanticipated tax liability shocks, and for 6 quarters before its implementation, to 24 quarters thereafter in the case of anticipated shocks.

\subsection{Benchmark Results}

Figure 3 reports the benchmark results. We discuss first the impact of an unanticipated tax cut shown in the left column of the figure. A surprise tax cut sets off a major expansion of the economy. According to our estimates, a 1 percent tax cut is associated with a 2 percent peak increase in GDP per capita. The increase in output occurs gradually over time with the peak being reached 10 quarters after the cut in taxes. Thereafter, output remains above trend for an extended period that goes beyond the 6 years forecast horizon illustrated in Figure 3. The increase in output is significantly positive at all but the second and third quarter and the confidence interval is narrow at all forecast horizons.

\footnotetext{
${ }^{8}$ Mertens and Ravn (2008) estimate a larger dimensional VAR which also includes consumer durables. The results are for al intents and purposes identical to those reported here.

${ }^{9}$ We report 68 percent confidence intervals due to the use of a non-parametric bootstrap.
} 
Private sector consumption also increases and the size of its peak response is similar to the size of the peak response of output, corresponding to a 2 percent increase above trend. Consumption, however, tends to increase slightly faster than output, and 6 years after the tax cut, consumption is still around 0.75 percent above trend. The increase in consumption is significantly positive at all forecast horizons.

By far the most elastic response is associated with private sector investment, which we estimate to increase by as much as 10 percent relative to its trend. As for output, the peak increase occurs 10 quarters after the cut in taxes. This indicates a large supply side impact of tax changes. One noticeable feature of the investment dynamics is that while its peak response is much larger than that of output and consumption, the response is also significantly less persistent. Such dynamics of investment would appear consistent with standard model of capital accumulation if tax changes affect directly the return on capital.

The impact on hours worked, instead, is estimated to be close to zero until around a year and a half after the change in taxes. After that, hours worked increases gradually and its peak response, which occurs 10 quarters after the tax cut, corresponds to approximately a 1 percent increase above trend. This gradual increase in hours worked indicates a much less significant labor market impact of tax shocks than the impact on goods markets. Another aspect of the labor market impact is the effect on real wages. The real wage response to fiscal policy shocks is often seen as a litmus test of business cycle theories because it reflects the movements in labor supply relative to labor demand. We find that (before tax) real wages rise gradually but very persistently after a cut in taxes.

Our estimates of the impact of unanticipated tax liability changes on output are similar to the univariate results of Romer and Romer (2010) and to the impact of a "basic government revenue shock" estimated by Mountford and Uhlig (2009). Relative to the estimates of Blanchard and Perotti (2002), the response of output to tax liability shocks occurs more gradually than their structural VAR estimate. However, our results are similar to theirs in terms of the persistence of the output response.

The right column of Figure 3 illustrates the impulse responses to an anticipated tax cut assuming a 6 quarter anticipation period. We find strong evidence of anticipation effects. During the pre-implementation period, an anticipated tax cut gives rise to significant declines in output, invest- 
ment, and in hours worked. The drop in aggregate output reaches its maximum 1 year before the implementation of the tax cut where output is estimated to be 1.5 percent below trend. The most dramatic anticipation effects relate to the impact on aggregate investment which drops 4 percent below trend 4 quarters before the tax cut is implemented. The anticipation effect on hours worked is also very pronounced, with hours worked falling 2 percent below trend and remaining below trend throughout the pre-implementation period.

The effects of the tax cut announcement on consumption and real wages are quite different from the effects on output, investment and hours worked. We find that the real wage if anything increases during the pre-implementation period, while consumption remains roughly unaffected by the tax announcement apart from a temporary drop 5 quarters before the tax cut is implemented. The impact on real wages makes it unlikely that the estimates are significantly contaminated by the lack of control for other structural shocks such as monetary policy shocks, a point that we will return to.

Once taxes are cut, the dynamics of the variables resemble the dynamics that follow after an unanticipated tax cut. Peak effects, however, occur slightly earlier for anticipated tax cuts. Output starts rising 3 quarters after the tax cut is implemented and reaches a peak increase that corresponds to a 1.5 percent rise above trend 8 quarters after the implementation of the tax cut. Investment reaches a 10 percent peak rise over trend 9 quarters after the implementation date. Hours worked rise slowly but eventually expands 1 percent above trend one year after the tax cut is implemented while the increase in the real wage during the pre-implementation period persists after taxes are cut.

The lack of an anticipation effect on consumption is in line with previous estimates in the literature. Poterba (1988) and Heim (2007) find no significant consumption response to announcements of future tax changes while Parker (1999) and Souleles (2002) find that consumption reacts to the implementation of pre-announced tax changes. According to our results the lack of anticipation effects on consumption is not indicative of the absence of adjustments to announcement of changes in future taxes since we find strong pre-implementation effects on output, investment, and hours worked. Romer and Romer (2010), in contrast, find only mild evidence of expectational effects when examining whether the expected present value of future not yet implemented tax changes affects the current level of aggregate GDP. A main difference between their approach and ours is that while we control for the anticipation horizon, Romer and Romer (20010) examine whether the present 
value of future tax changes affect current output regardless of their remaining anticipation lag of the pre-announced tax changes. It is hard to see that there are any reasons for why for example a tax change 2 quarters out in the future should have the same impact as, say, a tax change 6 quarters out in the future. Our results shows quite clearly that there are important anticipation effects when we take into account the anticipation horizon. ${ }^{10}$

Mountford and Uhlig (2009) identify the impact of a pre-announced government revenue shock using an "ex-post" identification approach based on sign restrictions. In particular, they examine the impact of a government tax revenue shock that takes place one year out in the future with the restriction that the shock is orthogonal to "business cycle" shocks and monetary policy shocks. In contrast to our findings, they find that a pre-announced revenue increase is associated with a preimplementation increase in output, while their estimates of the impact on investment agree with our results. Their identification strategy is fundamentally different from ours as they do not include currently available information about future tax liability changes. For that reason, it is perhaps not surprising that they find a different impact of pre-announced fiscal policy shocks. ${ }^{11}$

Our results appear consistent with strong supply side effects of tax changes. The strong decline in investment and the drop in hours worked in response to a pre-announced tax cut is consistent with the idea that future lower taxes motivate firms to delay purchases of capital goods and gives rise to intertemporal substitution of labor supply. Indeed, Mertens and Ravn (2010a) show that a DSGE model can account quite precisely for the dynamics of output, investment, and hours worked that follow after unanticipated and anticipated changes in taxes. At the same time, the results do not appear easily compatible with the idea that the lack of consumption response to announcements

\footnotetext{
${ }^{10}$ There are several other differences between our analysis and that of Romer and Romer (2010). We control for the interrelationships between the vector of endogenous variables, while Romer and Romer (2010) carry out univariate regressions. Our analysis allows for a different impact of implemented changes in unanticipated and anticipated tax shocks while Romer and Romer (2010) restrict these to have identical impact apart from the possible impact of lagged news.

${ }^{11}$ Moreover, as discussed by Leeper, Walker and Yang (2008), their identification is applied to government tax revenue rather than to tax liabilities relative to GDP. They assume that government revenue remains constant from the announcement date until the implementation date. Thus, to the extent that tax revenue is derived from income taxation, the pre-implementation increase in output that they estimate in response to a future tax revenue increase implies that tax rates must adjust during the pre-implementation period.
} 
of future tax changes can be interpreted as evidence of a significant share of liquidity constrained households. In particular, one would think that the ensuing increase in real wages would stimulate liquidity constrained households to work harder and therefore increase their consumption. For those reasons, we believe that the results of our exercise are important for understanding better the impact of fiscal policy shocks and for the development of macroeconomic theory.

\subsection{Sensitivity to the Anticipation Horizon}

The above analysis assumes pre-announced tax changes can impact on $X_{t}$ from a maximum of 6 quarters before their implementation. This length of the anticipation period corresponds to the median anticipation lag in the data. However, there is quite some variation in the anticipation lags and it is therefore interesting to examine how the results depend on the assumed anticipation horizon.

Figure 4 illustrates the impact of an anticipated tax liability cut on aggregate GDP when we vary the maximum anticipation horizon, between 4 and 10 quarters. In each case, we reestimate equation (2) for $K=4,6,8,10$, and then plot the resulting impulse response function. Regardless of the assumed anticipation horizon, the pre-implementation period is characterized by a drop in output and, once the tax cut is implemented, the tax cut stimulates the economy. However, the depth of the pre-implementation downturn and the size of the post-implementation expansion are sensitive to $K$. In particular, the longer the assumed maximum anticipation horizon (within reasonable limits), the deeper is the pre-implementation downturn and the milder is the post-implementation expansion. ${ }^{12}$

These results reconcile our findings with those of Blanchard and Perotti (2002) who find little evidence of anticipation effects, but allow only for a one quarter anticipation horizon. Our estimates indicate that for longer, and empirically relevant anticipation horizons, there are significant preimplementation effects of pre-announced tax liability changes.

\subsection{Anticipation Effects of Surprise Tax Changes}

The timing convention that we adopt to identify anticipated tax changes is based on the difference between the dates at which tax laws were signed by the President and the implementation of the tax

\footnotetext{
${ }^{12}$ We find roughly the same results alternatively estimate the anticipation effects for, say, $K=10$, and plot the impulse responses for anticipated shocks under alternative assumptions regarding their anticipation lag.
} 
liability changes according to these laws. This identification scheme does not take into account that the private economy might have perceived the introduction of tax bills even before they became law. Such perceptions may occur due to promises made during election campaigns, commitments made in speeches, policy announcements etc. If such considerations are significant, our results regarding the existence of anticipation effects and the differential impact of anticipated and unanticipated tax shocks would be questionable.

We examine the relevance of this issue by investigating whether there is any systematic evidence of responses to leads of surprise tax shocks. If the public had good information about tax changes before their implementation, we should find that these "anticipated surprise tax shocks" give rise to much the same adjustment of the economy as the tax shocks that we identify as anticipated on the basis of the timing convention. We estimate the following model:

$$
X_{t}=A+B t+C(L) X_{t-1}+D(L) \tau_{t}^{u}+\sum_{i=1}^{K} G_{i} \tau_{t, i}^{a}+\sum_{i=1}^{K} H_{i} \tau_{t+i}^{u}+e_{t}
$$

which allows for anticipation effects of surprise tax shocks.

Figure 5 illustrates the impact of a one percentage point decrease in $\tau_{t+6}^{u}$ on output and on investment. For comparison, this figure also shows the estimates of the impact of anticipated tax changes from this regression. In contrast to the impact of the impact of anticipated tax shocks identified using the timing convention, we find no evidence that surprise tax shocks impact on output or investment prior to their implementation. Thus, there is little evidence to suggest that surprise tax changes were systematically anticipated by the private sector. This does not preclude the possibility that specific surprise tax changes were anticipated nor that some of the anticipated tax changes were expected before they became law. For example, ERTA 1981 was proposed prior to Reagan's election and RA 1964 was proposed by Kennedy already in 1962. On the other hand, agents may have been skeptical about the likelihood that these proposals were actually to be implemented before they became laws. In any case, the evidence presented here is supportive of our timing based assumptions regarding the measurement of anticipated tax shocks when evaluated across tax changes. 


\section{Robustness Analysis}

This section provides a detailed robustness analysis. We wish to examine whether the findings regarding the stimulating impact of implemented tax cuts and the pre-implementation negative impact of anticipated tax cuts are sensitive to key aspects of our analysis.

\subsection{Exogeneity of the Tax Shocks}

The first issue that we address is endogeneity of the tax liability changes. The narrative account identification of fiscal shocks that we have adopted does address endogeneity and we eliminated all tax liability changes that Romer and Romer (2007) categorize as endogenous responses to the current or projected state of the economy. However, one may still worry that this does not completely eliminate the possibility that there is some endogeneity left in the tax changes that these authors deem exogenous.

Ideally one would wish to examine the exogeneity of each single tax act in isolation but this is not feasible statistically. Instead, we group the tax liability changes according to their motivation, that is whether they were ideologically based or introduced to address deficit concerns, and according to whether they were anticipated or not. We test for predictability of the tax liability changes using an ordered probit approach. Let $\widehat{\tau}_{t}^{s}$ measure the tax liability change of type $s$ announced at date $t$ where $s$ refers to the motivation of the tax change and to whether it refers to a surprise tax change or an anticipated tax change. ${ }^{13}$ We then define the variable $y_{t}^{s}$ as:

$$
y_{t}^{s}=\left\{\begin{array}{c}
-1 \text { if } \widehat{\tau}_{t}^{s}<0 \\
0 \text { if } \widehat{\tau}_{t}^{s}=0 \\
1 \text { if } \widehat{\tau}_{t}^{s}>0
\end{array}\right\}
$$

Thus, $y_{t}^{s}$ is a dummy variable that takes on on the value -1 when tax cuts are announced, 0 when there are no tax liability changes, and the value 1 when tax increases are announced. We then test whether this variable is predictable on the basis of past data on the vector of observables $X_{t}$ (output, consumption, investment, hours worked and real wages) using ordered probit regressions.

\footnotetext{
${ }^{13}$ Since the hypothesis is that preannounced tax changes affect the economy before the implementaiton date, it is important that the tax liability hanges are dated by the announcement dates rather than the implementation dates.
} 
Since most of the variables in $X_{t}$ are trending, these tests are carried out using detrended values of $X_{t}$ and each regression allows for 4 lags of $X_{t}$ to enter the probit regressions. ${ }^{14}$

Table 1 reports the values of likelihood ratio tests that the coefficients pertaining to the lags of $X_{t}$ are all equal to zero and the corresponding $p$-values of these statistics. The hypothesis that announcements of tax liability changes taken as one group are predictable can be rejected at the 95 percent level indicating lack of predictability of the tax changes. When we look at the subsets of the tax liability changes, the evidence in favor of exogeneity is very strong for ideologically based changes in taxes regardless of their timing. Taken as one group or separated into surprise tax changes or anticipated tax changes, the $p$-values of the test that lags of $X_{t}$ have no predictive power for ideologically based tax liability changes are all above 99 percent. Thus, we find no evidence to indicate that changes in taxes motivated by long term growth, fairness, or other ideological reasons can be predicted.

The results for deficit driven tax changes are instead more mixed. When we look at this type of tax changes without distinguishing between the announcement of concurrent or future tax changes, the $p$-value of the likelihood ratio test statistic is 48.2 percent. Decomposing these tax changes by the timing, the $p$-value for non-predictability of unanticipated tax changes is above 99 percent while it is 9.5 percent for the announcements of future tax changes. However, as far as the latter regression is concerned, there is no single element of the vector of lagged values of $X_{t}$ that individually has any predictive power for $y_{t}^{s}$. Thus, the evidence against the hypothesis that announcements of future deficit driven tax shocks are exogenous is, at best, weak.

We take a conservative approach to these results. Although the evidence against exogeneity of the tax changes is at best only mild as far as pre-announced deficit driven tax liability changes are concerned, we repeat the estimation of the impact of tax changes using only ideologically based tax acts (see Table A.1 for the classification of the tax shocks according to the motivation of their introduction). Figure 6 shows the impulse responses for this alternative tax shock measure. The results are robust. We find a slightly smaller impact of surprise tax changes than the benchmark

\footnotetext{
${ }^{14}$ We repeated our analysis using lower and higher order lag polynomials of $X_{t}$, using linear regressions, and using simple probits (which test for endogeneity of the timing of the tax announcements). The results were in line with those reported here.
} 
estimates (although the estimates are within the confidence intervals of the benchmark estimates at most forecast horizons) but the finding that anticipated tax shocks give rise to a pre-implementation drop in output and in investment is, if anything, even stronger when deficit driven tax changes are eliminated. In particular, we now find a 7 percent drop in aggregate investment 4 quarters before the implementation of the tax cut as compared to 4 percent in the benchmark case. Thus, while deficit driven tax changes may be partially endogenous, eliminating them from the sample does not overturn the key results of our analysis.

\subsection{Stability Across Tax Acts}

Another potential problem is that the results may derive from particular tax acts rather than being robust across tax acts. High sensitivity to particular tax acts would indicate that the results cannot be viewed as general, but derive from features special to particular tax acts such as the economic circumstances under which they were introduced.

We examine this issue by eliminating particular tax acts from the sample. Three tax acts stand out as particularly important: The Kennedy tax initiative (the Revenue Act of 1964, RA 1964 in short), the Reagan tax act (ERTA 1981), and the Bush tax initiatives (the Economic Growth and Tax Relief Reconciliation Act of 2001 and the Jobs and Growth Tax Relief Reconciliation Act of 2003, EGTRRA 2001 and JGTRRA 2003). These tax acts included large changes in tax liabilities and also included several pre-announced changes in taxes. They are therefore prime candidates for having particularly important consequences for our results and, thus, we examine how the results of our exercise are sensitive to their elimination. We estimate the following regression:

$$
X_{t}=A+B t+C(L) X_{t-1}+D(L) \widehat{\tau}_{t}^{u}+F(L) \widehat{\tau}_{t, 0}^{a}+\sum_{i=1}^{K} G_{i} \widehat{\tau}_{t, i}^{a}+e_{t}
$$

where $\widehat{\tau}_{t}^{u}$ and $\widehat{\tau}_{t, i}^{a}$ denote the tax shocks when we eliminate the tax liability changes (i.e. when we set these tax shocks equal to 0) associated with either the Kennedy tax act, the Reagan tax act, or the Bush tax acts.

The results for output, investment and real wages are reported in Figure 7 together with the benchmark estimates and their confidence intervals. Exclusion of ERTA 1981 implies slightly smaller responses of output and investment but their shapes are very similar to the benchmark estimates. 
The most significant impact of eliminating ERTA 1981 is that we find a much larger real wage increase to implemented anticipated tax cuts. Excluding RA 1964 has little consequence at all apart from the real wage response to surprise tax cuts being less strong than in the benchmark case. Finally, when we eliminate EGTRRA 2001 and JGTRRA 2003 we find even larger output, investment and real wage increases after surprise tax cuts than in the benchmark regressions while the effects of anticipated tax cuts are basically unaffected. In summary, although the quantitative impact of tax shocks depends somewhat on the tax acts that are considered, the main results are robust to eliminating particular tax acts.

We also note that we find a consistent tendency for the real wage to increase during the preimplementation period in response to an anticipated tax cut. This result is important because it addresses indirectly a concern that the estimated pre-implementation drop in activity derives from lack of control for monetary policy variables (an issue that we examine in detail below). In particular, since the ERTA 1981 coincided with the Volcker disinflation, one might worry that our results are sensitive to the omission of monetary policy variables. However, not only do we find that the results are robust to eliminating this tax act, but the rise in the real wage also appears at odds with this hypothesis. The reason is that standard monetary models would predict that the real wage should decline in response to a contractionary monetary policy shock (such as the Volcker experiment) due to the ensuing increase in the markup. We find instead a rise in the real wage which lends no support to this hypothesis.

\subsection{Permanent vs. Temporary Tax Changes}

The tax shock measure that we study aggregates together tax liability changes that were meant to be permanent and tax changes meant to be temporary. In theory one would like to treat these tax changes separately although the distinction in practice is less clear-cut since tax changes that were meant to be permanent have occasionally been reversed subsequently (and in some cases, tax changes meant to be temporary have subsequently been extended).

Nevertheless, it is of interest to examine whether this distinction matters for the results. Table

A.1 records the persistence of the tax liability changes and we note that eliminating temporary tax changes corresponds to removing in total 10 tax liability changes from the sample out of which 
the Jobs and Growth Relief Tax Reconciliation Act of 2003 is the most important one. Figure 8 shows the responses of aggregate output, consumption and investment to the tax shocks when we consider only those tax changes that were explicitly meant to be permanent. The results are qualitatively very similar to those that we reported in Section 3. Quantitatively, we find a larger response of output and its components to surprise tax changes when we consider only permanent tax changes, a finding that appears natural. The impact of anticipated tax shocks is also quite similar to the benchmark results, although we now find some evidence to suggest a pre-implementation drop in private sector consumption. Nevertheless, as in the benchmark results, the anticipation effects are much more pronounced for output and investment than for consumption.

\subsection{Other Structural Shocks}

Finally, we consider whether our results are affected by the lack of control for other structural shocks. We wish to emphasize that lack of control for other structural shocks is only a concern due to small sample considerations.

\subsubsection{Monetary Policy Shocks}

One of the largest sequence of tax shocks in our sample, the Reagan tax cuts, coincides with an important monetary policy intervention, the Volcker disinflation. The deliberate disinflationary period of the Volcker chairmanship took its course during the period November 1980 to June 1982 (see Goodfriend and King, 2005). During this period, interest rates were hiked and by mid-1981 the federal funds rate peaked at 19 percent while the Tbond rate peaked a few months later at more than 15 percent. Thus, when Reagan signed the ERTA in August 1981, it was in the midst of the Fed's attempts to stabilize inflation. We have already provided evidence above in Section 4.1 that eliminating ERTA 1981 from the sample does not substantially alter the results. Therefore, we are skeptical about contamination during this particular experiment, but this does not exclude the possibility that there is a more systematic problem when omitting controls for monetary policy.

In order to address this issue we augment the VAR with variables that allow us to control for monetary policy shocks and introduce identifying assumptions adopted in the SVAR literature to derive estimates of the monetary policy shocks and their effects. We estimate the following VAR: 


$$
\widetilde{X}_{t}=A+B t+C(L) \tilde{X}_{t-1}+D(L) \tau_{t}^{u}+F(L) \tau_{t, 0}^{a}+\sum_{i=1}^{K} G_{i} \tau_{t, i}^{a}+e_{t}
$$

where $\widetilde{X}_{t}$ consists of the following vector of variables:

$$
\widetilde{X}_{t}=\left[y_{t}, i_{t}, z_{t}, r_{t}, n_{t}\right]^{\prime}
$$

$z_{t}$ is a vector of variables consisting of the (annualized) inflation rate, and the commodity price inflation rate, $r_{t}$ is the federal funds rate, and $n_{t}$ denotes non-borrowed reserves (see the Appendix for precise definitions and sources). Given lack of data for non-borrowed reserves for the earliest part of the sample, we restrict the sample period to 1959:1-2006:4. This VAR is estimated using 4 lags of the vector of endogenous variables. This introduces a large number of parameters to be estimated and for that reason we eliminate consumption from the VAR. For the same reason, we set $R=6$.

We assume that the interest rate is affected contemporaneously by all the variables in the VAR apart from non-borrowed reserves. We also allow the interest rate to react contemporaneously to innovations to the tax shocks. The variables ordered before the interest rate in the VAR (i.e. all but non-borrowed reserves) are assumed not to react contemporaneously to monetary policy shocks while non-borrowed reserves is not constrained this way. These assumptions identify the monetary policy shock as the innovation to the federal funds rate given a Cholesky decomposition of the covariance matrix of $e_{t}$, see Christiano, Eichenbaum and Evans (1996).

Figure 9 illustrates the impact of the tax shocks on output, investment, inflation, and the federal funds rate. The results are very similar to the benchmark estimates. Interestingly, we find that the federal funds rate initially decreases in response to a surprise cut in taxes but then eventually returns to its normal level 1.5-2 years after the tax cut. As in the benchmark estimates, the anticipated tax cut gives rise to a pre-implementation drop in aggregate output and investment as well as in the inflation rate and the nominal interest rate. The associated drop in aggregate investment during the pre-implementation period is slightly larger than in the benchmark estimates of Section 3 while the output drop is slightly smaller.

All in all, we find a remarkable degree of robustness of the benchmark results. Thus, our estimates of the impact of tax policy shocks do not appear contaminated by the lack of control for monetary policy variables. 


\subsubsection{Government Spending}

One may also worry about possible correlations of the tax changes with other fiscal policy shocks. In particular, it is possible that the results are sensitive to in-sample correlation with shocks to fiscal spending. We address this issue in the same fashion as above by controlling directly for government spending shocks. We estimate the following VAR:

$$
\widehat{X}_{t}=A+B t+C(L) \widehat{X}_{t-1}+\sum_{i=1}^{4} H(L) W_{i t}+D(L) \tau_{t}^{u}+F(L) \tau_{t, 0}^{a}+\sum_{i=1}^{K} G_{i} \tau_{t, i}^{a}+e_{t}
$$

where $\widehat{X}_{t}$ is the following vector of variables:

$$
\widehat{X}_{t}=\left[g_{t}, v_{t}, y_{t}, c_{t}, i_{t}\right]^{\prime}
$$

The variable $g_{t}$ denotes gross federal purchases of goods and services, and $v_{t}$ denotes federal revenues (both measured in real per capita terms, see the appendix for precise definitions). As in Burnside, Eichenbaum and Fisher (2004) and Ramey (2008), the fiscal VAR includes controls for (scaled) Ramey and Shapiro (1998) war dummies augmented with a 9/11 dummy as in Ramey (2008). These dummies, captured by $W_{i t}$, control for changes in federal military spending associated with the Korean war, the Vietnam war, the Carter-Reagan military buildup, and 9/11. The war dummies are equal to zero at all dates apart from 1950:3 for $W_{1 t}, 1965: 1$ for $W_{2 t}, 1980: 1$ for $W_{3 t}$ and 2001:3 for $W_{4 t}$. We normalize $W_{1,1950: 3}=1$ while following Ramey $(2008)$, we set $W_{2,1965: 1}=0.3$, $W_{3,1980: 1}=0.1$ and $W_{4,2001: 3}=0.1$, see also Burnside, Eichenbaum and Fisher (2004). Government spending shocks are thus measured by the war dummies which provides a symmetric treatment to the narrative approach of the measurement of the tax shocks. One slight worry is changes government spending may also be associated with anticipation effects. It is beyond the scope of this paper to evaluate this problem but Ramey (2008) provides some evidence of the relevance of this issue.

The responses to a 1 percent tax cut when we control for government spending are reported in Figure 10. The impact on output, consumption, and investment are practically identical to the benchmark case. An anticipated tax cut gives rise to a pre-implementation drop in output and in investment while consumption is roughly constant throughout the pre-implementation period. As in the benchmark estimates, once taxes are eventually cut, there is a significant rise in output and its components. Thus, we find no evidence to suggest that our results are contaminated by lack of 
control for government spending shocks.

Finally, we note that an unanticipated tax shock is associated with a temporary drop in government spending, a finding that would be consistent with a "starving the beast" hypothesis regarding the government spending effects of tax cuts. This result, however, is sensitive to the inclusion of changes in tax liabilities that are related to concerns about inherited government deficits. Eliminating these tax changes, we find that government spending increases after a cut in taxes which is consistent with the estimates of Romer and Romer (2009).

\section{Tax Shocks and the U.S. Business Cycle}

We now examine if the tax shocks have had important business cycle consequences. We carry out this analysis using a counterfactual framework. In particular, we simulate the estimated VAR process setting the vector $\widehat{e}_{t}$ equal to zero and using the point estimates of the estimated parameter vectors. The resulting time-series for the observables are then Hodrick-Prescott filtered (assuming a value of the smoothing parameter of 1600). These counterfactual time-series are then compared with the actual time series for the observables.

The results of this exercise using the benchmark VAR are reported in Figure 11. We show the counterfactual time series for output, consumption and investment for three different simulations. In the first simulation we allow only for surprise tax shocks thus setting $\tau_{t, i}^{a}=0$ for all $t$ and all $i=0,1, . ., K$. These results are reported in panel A. In the second case we allow only for anticipated tax shocks thus setting $\tau_{t}^{u}=0$ for all $t$. These results are shown in panel B. Finally, in the third simulation, we allow for both types of tax shocks. In all cases, the counterfactual time series are shown with thick lines while the actual time series are illustrated with the lighter lines. In each figure, grey areas illustrate recessions according to the NBER datings.

Both anticipated and unanticipated tax shocks have provided important impulses to the business cycle. Surprise tax changes were important impulses to the business cycle during three episodes. During the early to mid 1960 's, the 2.55 percent tax liability cut contained in RA of 1964 provided a major stimulus to the economy which accounts for a large fraction of the boom in the U.S. economy during the mid 1960's. The 1.23 percent tax cut contained in the Revenue Act of 1971 contributed to the pre-OPEC I boom of the U.S. economy in the early 1970's. Finally, the 2.86 percent tax liability 
cut associated with JGTRRA 2003 provided a major boost to the economy in the mid 2000's.

Anticipated tax liability changes were particularly relevant impulses to the business cycle during the early 1980's recession, the expansion that followed thereafter, and during the early 2000's. Particularly interesting is the 1980's episode where we find that ERTA 1981 and the Social Security Amendments of 1977 together had a large impact on the U.S. economy. The Social Security Amendments of 1977 (signed by Carter in December 1977) included a 0.56 percent tax increase implemented in 1981. This tax liability change had an expansionary effect on the economy prior to its implementation but provided a negative stimulus once implemented in 1981. ERTA 1981, signed by Reagan in August 1981, was associated with major tax cuts implemented gradually from 1982 to 1984. These anticipated tax cuts had a negative impact on the U.S. economy from late 1981 up till the end of 1983, the same time as the negative effects of the Social Security Amendments of 1977 were setting in. When the Reagan tax cuts were eventually implemented through 1982 to 1984, it provided a major stimulus to the economy during the mid 1980's. Together, these anticipated tax cuts therefore stimulated the economy prior to 1981, gave rise to a contractionary effects from 1981 to late 1983, and helped the economy recover thereafter. Quantitatively, our results indicate that the early 1980's recession was to a large extent caused by fiscal policy rather than induced by tight monetary policy during the Volcker monetary regime.

Anticipation effects are also relevant in the case of EGTRRA 2001 and JGTRRA 2003 signed by Bush in June 2001 and in May 2003, respectively. The former introduced a 0.80 percent cut in tax liabilities in the first quarter of 2002 while the latter introduced anticipated tax increases in the third quarter of 2004 (a 1.70 percent increase) and in the first quarter of 2005 (a 0.56 increase). In agreement with the simulations of House and Shapiro (2006), we find that the anticipation effects of the first of these tax acts contributed to the slow recovery from the 2001 U.S. recession, while the implementation of the tax cut helped stimulate the economy from 2002 onwards. Ironically, the anticipation effects associated with the tax increases incorporated in JGTRRA 2003 further stimulated the economy during the pre-implementation period (2003q2 - 2004q3) until its implementation eventually starts having a negative impact from the end of 2004 onwards. ${ }^{15}$

\footnotetext{
${ }^{15}$ Note that we exclude parts of the tax changes in EGTRRA 2001 since Romer and Romer (2007) categorize the temporary tax cut as an endogenous response to the state of the business cycle.
} 
When we allow for both types of tax shocks, see panel $\mathrm{C}$, we find that they have accounted for around 20 percent of the in-sample variance of output and its components at business cycle frequencies. Moreover, the correlation between the counterfactual time-series and the actual timeseries is high (around 56 percent for output, and 48 percent for consumption and investment). Thus, we conclude that tax shocks play a major role as business cycle impulses, a finding that is in line with McGrattan (1994).

Perhaps the most controversial result of this exercise is the importance of anticipated tax changes for the early 1980's recession. To establish the robustness of this result, Figure 12 reports the counterfactual time-series for output based on the VAR in equation (4) where we control for monetary policy. In this figure we also show the counterfactual output series that derives from allowing only for monetary policy shocks. Our results are robust. At the trough of the early 1980's contraction, output is 4.6 percent below trend. According to the benchmark estimates, the tax shocks by themselves give rise to a 3.3 percent drop in output and the anticipated tax cuts account for almost all of this drop. When we reestimate the VAR allowing for monetary variables, tax shocks give rise to a 2.6 percent drop in output again with most of the action coming from anticipated tax shocks. By contrast, the monetary policy shocks account for a maximum one percent drop in output. Moreover, in the counterfactual experiment, the tax shocks can account for 27 percent of the output variance when we introduce monetary variables in the VAR, and estimate that is even higher than the benchmark estimate. Thus, the finding that tax shocks were key for accounting for the early 1980's recession is robust and is not due to lack of control for monetary policy shocks.

\section{Conclusions}

We have investigated the dynamic effects of tax liability changes in the U.S. during the postwar period. We distinguished between anticipated and unanticipated tax shocks on the basis of a timing convention. In particular, we assume that tax shocks that were introduced more than 90 days after they became law were anticipated while tax liability changes implemented within 90 days of becoming law are classified as surprise tax shocks. We have documented that unanticipated tax cuts give rise to a major stimulus to the economy which is reflected in persistent increases in output, consumption, investment and, to a smaller extent, hours worked. Anticipated tax cuts also stimulate the economy 
once taxes are cut, but during the pre-implementation period, we find that output, investment and hours worked drop while consumption is roughly unchanged. A number of earlier studies have documented little impact of tax announcements on consumption until taxes are eventually changed, a finding that is consistent with our results. The finding of important anticipation effects on output, investment and hours worked is new to the literature, however. Moreover, we showed through extensive robustness analysis that these results do not derive from special assumptions that we made, nor that they are caused by endogeneity of the tax changes or by missing control for other popular structural shocks.

Tax shocks have provided important impulses to the U.S. business cycle. In particular, we showed that the two tax shocks have been important for several business cycle episodes in the U.S. Particularly interesting may be our finding that tax changes were key for understanding the early 1980's recession and the mid-1980's expansion of the U.S. economy. The tax shocks altogether can account for around 20-25 percent of the in-sample variance of (detrended) output, an estimate that is at least as large as the contribution of other popular candidates for business cycle impulses.

Our results regarding the presence of anticipation effects have important consequences. First, it provides some empirical evidence towards which theories of anticipation effects can be evaluated. Preexisting evidence has been scarce on this since it has mainly been concerned with consumption responses to pre-announced tax changes and has found little impact on consumption of such tax announcements (until they become implemented). Therefore, our results regarding the output, investment, and labor market impact of tax announcements provide some valuable findings that one can use for model evaluation. Mertens and Ravn (2010a) carry out such an exercise. Secondly, our results may also have some relevance for the recent interest into the "news" view of business cycles, see e.g. Beaudry and Portier (2004, 2006), Cochrane (1994), Danthine, Donaldson and Johnsen (1998), den Haan and Kaltenbrunner (2009), or Jaimovich and Rebelo (2006). An important obstacle to empirical tests for a news driven business cycle theory is that expectations are inherently difficult to estimate as they are unobserved by the econometrician, but we overcome this difficulty in our application to fiscal policy. Our finding that a pre-announced tax cut gives rise to a preimplementation contraction in the economy may be important for understanding how news shocks help shape fluctuations in the economy. 
It would be interesting to extend our analysis to other parts of fiscal policy. Ramey (2008) provides some first evidence that anticipation effects may account for some of the more puzzling recent findings about the impact of government spending shocks that derive from VAR based measures of fiscal shocks. In particular, she shows that the fiscal shocks identified by VAR based methods (that rely on decision lags for identification) appear to be predictable on the basis of publicly available forecasts of changes in fiscal policy. Moreover, by simulating a DSGE model she shows that ignoring such anticipation effects may lead to seriously biased estimates of the impact of fiscal policy shocks. It would therefore be interesting to examine also whether there are signs of such anticipation effects in the data using similar methods to those that we have proposed in this paper.

\section{References}

Auerbach, Alan J., 1989, "Tax Reform and Adjustment Costs: The Impact on Investment and Market Value", International Economic Review vol.30(4), 939-962.

Beaudry, Paul, and Franck Portier, 2004, "An Exploration into Pigou's Theory of Cycles", Journal of Monetary Economics vol.51(6), 1183-1216.

Beaudry, Paul, and Franck Portier, 2006, "Stock Prices, News, and Economic Fluctuations", American Economic Review vol.96(4), 1293-1307.

Blanchard, Olivier J., 1981, "Output, the Stock Market, and Interest Rates", American Economic Review vol.71(1), 132-143.

Blanchard, Olivier J., and Roberto Perotti, 2002, "An Empirical Investigation of the Dynamic Effects of Changes in Government Spending and Taxes on Output", Quarterly Journal of Economics vol.117(4), 1329-1368.

Burnside, Craig, Martin Eichenbaum and Jonas D. M. Fisher, 2004, "Fiscal Shocks and Their Consequences", Journal of Economic Theory 115, 89-117.

Christiano, Lawrence, Martin Eichenbaum, and Charles Evans, 1996, "The Effects of Monetary Policy Shocks: Evidence from the Flow of Funds", Review of Economics and Statistics 78(1), 16-34. 
Cochrane, John, 1994, "Shocks", Carnegie-Rochester Series on Public Policy 41, 295-364.

Danthine, Jean Pierre, John B. Donaldson and Thore Johnsen, 1998, "Productivity Growth, Consumer Confidence and the Business Cycle", European Economic Review 42, 1113-1140.

Den Haan, Wouter J., and Georg Kaltenbrunner, 2009, “Anticipated Growth and Business Cycles in Matching Models", Journal of Monetary Economics 56(3), 309-27.

Goodfriend, Marvin, and Robert G. King, 2005, "The Incredible Volcker Disinflation", Journal of Monetary Economics 52(5), 981-1015.

Hall, Robert E., 1971, "The Dynamic Effects of Fiscal Policy in an Economy with Foresight", Review of Economic Studies 38, 229-244.

Heim, Bradley T., 2007, "The Effect of Tax Rebates on Consumption Expenditures: Evidence from State Tax Rebates", National Tax Journal, 685-710.

House, Christopher L., and Matthew D. Shapiro, 2006, "Phased-In Tax Cuts and Economic Activity", American Economic Review 96(4), 1835-1849.

Jaimovich, Nir, and Sergio T. Rebelo, 2006, “Can News About the Future Drive the Business Cycle?", manuscript, Northwestern University.

Leeper, Eric M., Todd B. Walker and Shu-Chun Susan Yang, 2008, "Fiscal Foresight: Analytics and Econometrics", manuscript, Indiana University.

McGrattan, Ellen R., 1994, "The Macroeconomic Effects of Distortionary Taxation", Journal of Monetary Economics 33(3), 573-601.

Mertens, Karel, and Morten O. Ravn, 2008, "The Aggregate Effects of Anticipated and Unanticipated U.S. Tax Policy Shocks: Theory and Empirics", EUI working paper no. 2008/05.

Mertens, Karel, and Morten O. Ravn, 2010a, "Understanding the Aggregate Effects of Anticipated and Unanticipated Tax Policy Shocks", forthcoming, Review of Economic Dynamics. 
Mertens, Karel, and Morten O. Ravn, 2010b, "Measuring the Impact of Fiscal Policy in the Face of Anticipation: A Structural VAR Approach", Economic Journal 120(May), 393-413.

Mountford, Andrew, and Harald Uhlig, 2009, "What are the Effects of Fiscal Policy Shocks?", Journal of Applied Econometrics 24(6), 960-92..

Parker, Jonathan A., 1999, "The Reaction of Household Consumption to Predictable Changes in Social Security Taxes", American Economic Review vol.89(4), 959-973.

Perotti, Roberto, 2007, "Estimating the Effects of Fiscal Policy in OECD Countries", working paper no. 276 , IGIER.

Poterba, James M., 1988, "Are Consumers Forward Looking? Evidence from Fiscal Experiments", American Economic Review vol.78(2), 413-418.

Ramey, Valerie A., 2008, "Identifying Government Spending Shocks: It's All in the Timing", manuscript, University of California, San Diego.

Ramey, Valerie A., and Matthew D. Shapiro, 1998, "Costly Capital Reallocation and the Effects of Government Spending", Carnegie-Rochester Series on Public Policy vol.48, 145-194.

Romer, Christina D., and David H. Romer, 2007, "A Narrative Analysis of Postwar Tax Changes", manuscript, University of California, Berkeley.

Romer, Christina D., and David H. Romer, 2008, "A Narrative Analysis of Postwar Tax Changes", manuscript, University of California, Berkeley.

Romer, Christina D., and David H. Romer, 2009, "Do Tax Cuts Starve the Beast? The Effect of Tax Changes on Government spending", Brookings Papers on Economic Activity (Spring).

Romer, Christina D., and David H. Romer, 2010, "The Macroeconomic Effects of Tax Changes: Estimates Based on a New Measure of Fiscal Shocks", American Economic Review 100(3), 763-801.

Souleles, Nicholas S., 1999, "The Response of Household Consumption to Income Tax Refunds", American Economic Review vol.89(4), 947-958. 
Souleles, Nicholas S., 2002, "Consumer Response to the Reagan Tax Cut", Journal of Public Economics vol.85, 99-120.

Taylor, John B., 1993, Macroeconomic Policy in a World Economy, W.W. Norton: New York.

Yang, Shu-Chun Susan, 2005, "Quantifying Tax Effects Under Policy Foresight”, Journal of Monetary Economics 52(8), 1557-1168. 


\section{Appendix 1: Data: Definitions and Sources}

Table A.1: Tax Liability Changes

\begin{tabular}{|c|c|c|c|c|c|c|}
\hline Name & Signed & Effective & Type & Persistence & Motivation & Size \\
\hline 1. Social Security Amendments of 1947 & August 1947 & 1950 Q1 & Anticipated & Permanent & Deficit & 0.27 \\
\hline \multirow[t]{2}{*}{ 2. Revenue Act of 1948} & April 1948 & 1948 Q2 & Surprise & Permanent & Long run & -3.74 \\
\hline & April 1948 & 1948 Q3 & Surprise & Permanent & Long run & 1.83 \\
\hline 3. Social Security Amendments of 1950 & August 1950 & 1954 Q1 & Anticipated & Permanent & Deficit & 0.35 \\
\hline 4. Expiration of Excess Profits and & October 1951 & $1954 \mathrm{Q} 1$ & Anticipated & Permanent & Deficit & -0.35 \\
\hline \multicolumn{7}{|l|}{ Temporary Income Tax } \\
\hline \multirow[t]{2}{*}{ 5. Internal Revenue Code of 1954} & August 1954 & 1954 Q3 & Surprise & Permanent & Long run & -1.13 \\
\hline & August 1954 & $1954 \mathrm{Q} 4$ & Surprise & Permanent & Long run & 0.72 \\
\hline 6. Tax Rate Extension Act of 1958 & June 1958 & 1958 Q3 & Surprise & Permanent & Long run & -0.11 \\
\hline 7. Social Security Amendments of 1958 & August 1958 & 1960 Q1 & Anticipated & Permanent & Deficit & 0.36 \\
\hline 8. Federal-Aid Highway Act of 1959 & September 1959 & 1959 Q4 & Surprise & Temporary & Deficit & 0.12 \\
\hline 9. Social Security Amendments of 1961 & Jun 1961 & 1963 Q1 & Anticipated & Permanent & Deficit & 0.33 \\
\hline 10. Changes in Depreciation Guidelines & July 1962 & 1962 Q3 & Surprise & Permanent & Long run & -0.69 \\
\hline \multirow[t]{4}{*}{ and Revenue Act of 1962} & July 1962 & $1962 \mathrm{Q} 4$ & Surprise & Permanent & Long run & 0.45 \\
\hline & October 1962 & 1962 Q4 & Surprise & Permanent & Long run & -0.61 \\
\hline & October 1962 & 1963 Q1 & Surprise & Permanent & Long run & 0.45 \\
\hline & October 1962 & 1963 Q1 & Surprise & Permanent & Long run & 0.10 \\
\hline \multirow[t]{3}{*}{ 11. Revenue Act of 1964} & February 1964 & 1964 Q2 & Surprise & Permanent & Long run & -2.55 \\
\hline & February 1964 & 1964 Q3 & Anticipated & Permanent & Long run & 1.25 \\
\hline & February 1964 & 1965 Q1 & Anticipated & Permanent & Long run & -0.65 \\
\hline \multirow[t]{2}{*}{ 12. Excise Tax Reduction of 1965} & June 1965 & 1965 Q3 & Surprise & Permanent & Long run & -0.24 \\
\hline & June 1965 & 1966 Q1 & Anticipated & Permanent & Long run & -0.23 \\
\hline 13. Tax Adjustment Act of 1966 & March 1966 & $1966 \mathrm{Q} 2$ & Surprise & Permanent & Long run & 0.12 \\
\hline \multirow[t]{2}{*}{ 14. Public Law 90-26 } & June 1967 & 1967 Q3 & Surprise & Permanent & Long run & -0.66 \\
\hline & June 1967 & 1967 Q4 & Anticipated & Permanent & Long run & 0.46 \\
\hline
\end{tabular}


Table A.1 continued

\begin{tabular}{|c|c|c|c|c|c|c|}
\hline Name & Signed & Effective & Type & Persistence & Motivation & Size \\
\hline 15. Social Security Amendments of 1967 & January 1968 & 1971 Q1 & Anticipated & Permanent & Deficit & 0.33 \\
\hline \multirow[t]{2}{*}{ 16. Tax Reform Act of 1969} & December 1969 & 1971 Q1 & Anticipated & Permanent & Long run & -0.09 \\
\hline & December 1969 & 1972 Q1 & Anticipated & Permanent & Long run & -0.09 \\
\hline 17. Reform of Depreciation Rules & January 1971 & 1971 Q1 & Surprise & Permanent & Long run & -0.25 \\
\hline \multirow[t]{2}{*}{ 18. Revenue Act of 1971} & December 1971 & 1972 Q1 & Surprise & Permanent & Long run & -1.23 \\
\hline & December 1971 & 1972 Q2 & Anticipated & Permanent & Long run & 0.55 \\
\hline 19. 1972 Changes to Social Security & October 1972 & 1978 Q1 & Anticipated & Permanent & Deficit & 0.13 \\
\hline \multirow[t]{2}{*}{ 20. Tax Reform Act of 1976} & October 1976 & 1976 Q4 & Surprise & Permanent & Long run & 0.13 \\
\hline & October 1976 & 1977 Q1 & Surprise & Permanent & Long run & -0.04 \\
\hline 21. Tax Reduction and & May 1977 & 1977Q3 & Surprise & Permanent & Long run & -1.02 \\
\hline Simplification Act of 1977 & May 1977 & 1977Q4 & Anticipated & Permanent & Long run & 0.66 \\
\hline \multirow[t]{4}{*}{ 22. Social Security Amendments of 1977} & December 1977 & 1979 Q1 & Anticipated & Permanent & Long run & 0.36 \\
\hline & December 1977 & 1980 Q1 & Anticipated & Permanent & Long run & 0.06 \\
\hline & December 1977 & 1981 Q1 & Anticipated & Permanent & Long run & 0.56 \\
\hline & December 1977 & 1982 Q1 & Anticipated & Permanent & Long run & 0.05 \\
\hline 23. Revenue Act of 1978 & November 1978 & 1979 Q1 & Surprise & Permanent & Long run & -0.77 \\
\hline 24. Crude Oil Windfall Profit & April 1980 & 1980 Q2 & Surprise & Temporary & Long run & 0.30 \\
\hline \multirow[t]{2}{*}{ Tax Act of 1980} & April 1980 & 1981 Q1 & Anticipated & Temporary & Long run & 0.13 \\
\hline & April 1980 & $1982 \mathrm{Q} 1$ & Anticipated & Temporary & Long run & 0.13 \\
\hline 25. Economic Recovery Tax Act & August 1981 & 1981 Q3 & Surprise & Permanent & Long run & -0.84 \\
\hline \multirow[t]{4}{*}{ of 1981} & August 1981 & 1981 Q4 & Surprise & Permanent & Long run & 0.56 \\
\hline & August 1981 & 1982 Q1 & Anticipated & Permanent & Long run & -1.53 \\
\hline & August 1981 & 1983 Q1 & Anticipated & Permanent & Long run & -1.69 \\
\hline & August 1981 & 1984 Q1 & Anticipated & Permanent & Long run & -1.28 \\
\hline 26. Tax Equity and Fiscal & September 1982 & 1983 Q1 & Anticipated & Permanent & Deficit & 0.78 \\
\hline Responsibility Act of 1982 & & & & & & \\
\hline
\end{tabular}




\begin{tabular}{|c|c|c|c|c|c|c|}
\hline Name & Signed & Effective & Type & Persistence & Motivation & Size \\
\hline 27. Social Security Amendments & April 1983 & 1984 Q1 & Anticipated & Permanent & Deficit & 0.32 \\
\hline \multirow[t]{4}{*}{ of 1983} & April 1983 & 1985 Q1 & Anticipated & Permanent & Deficit & 0.21 \\
\hline & April 1983 & 1986 Q1 & Anticipated & Permanent & Deficit & 0.10 \\
\hline & April 1983 & 1988 Q1 & Anticipated & Permanent & Deficit & 0.31 \\
\hline & April 1983 & 1990 Q1 & Anticipated & Permanent & Deficit & 0.18 \\
\hline 28. Deficit Reduction Act of 1984 & July 1984 & 1984 Q3 & Surprise & Permanent & Deficit & 0.20 \\
\hline \multirow[t]{4}{*}{ 29. Tax Reform Act of 1986} & October 1986 & 1986 Q4 & Surprise & Permanent & Long run & 0.50 \\
\hline & October 1986 & 1987 Q1 & Surprise & Permanent & Long run & -0.16 \\
\hline & October 1986 & 1987 Q3 & Anticipated & Permanent & Long run & -0.42 \\
\hline & October 1986 & 1988 Q1 & Anticipated & Permanent & Long run & -0.15 \\
\hline 30. Omnibus Budget Reconciliation & December 1987 & 1988 Q1 & Surprise & Permanent & Deficit & 0.22 \\
\hline \multicolumn{7}{|l|}{ Act of 1987} \\
\hline 31. Omnibus Budget Reconciliation & November 1990 & 1991 Q1 & Surprise & Permanent & Deficit & 0.60 \\
\hline \multicolumn{7}{|l|}{ Act of 1990} \\
\hline 32. Omnibus Budget Reconciliation & August 1993 & 1993 Q3 & Surprise & Permanent & Deficit & 1.02 \\
\hline \multirow[t]{2}{*}{ Act of 1993} & August 1993 & 1993 Q4 & Surprise & Permanent & Deficit & -0.59 \\
\hline & August 1993 & 1994 Q1 & Anticipated & Permanent & Deficit & 0.19 \\
\hline 33. Tax Payer Relief Act and & August 1997 & $2000 \mathrm{Q} 1$ & Anticipated & Permanent & Deficit & 0.02 \\
\hline Balanced Budget Act of 1997 & August 1997 & $2002 \mathrm{Q} 1$ & Anticipated & Permanent & Deficit & 0.01 \\
\hline 34. Economic Growth and Tax Relief & June 2001 & 2002 Q1 & Anticipated & Permanent & Long run & -0.80 \\
\hline \multicolumn{7}{|l|}{ Reconciliation Act of 2001} \\
\hline 35. Jobs and Growth Tax Relief & May 2003 & 2003 Q3 & Surprise & Temporary & Long run & -2.86 \\
\hline \multirow[t]{2}{*}{ Reconciliation Act of 2003} & May 2003 & 2004 Q3 & Anticipated & Temporary & Long run & 1.70 \\
\hline & May 2003 & 2005 Q1 & Anticipated & Temporary & Long run & 0.56 \\
\hline
\end{tabular}

Source: Romer and Romer, 2007, 2008 and Bureau of Economic Analysis. Tax liability changes with more than 90 days difference between the signing of the legislation and their implementation are classified as anticipated tax liability changes. Sizes are measured by the implied tax liability impact divided by that quarter's current price GDP at the annual rate. 
Table A.2: Definitions of Variables

\begin{tabular}{|c|c|c|}
\hline Variable & Definition & Source \\
\hline Output & $\begin{array}{l}\text { Nominal GDP divided by its implicit deflator and by } \\
\text { population }\end{array}$ & Bureau of Economic Analysis \\
\hline Consumption & $\begin{array}{l}\text { Consumers nominal expenditure divided by its } \\
\text { its deflator and by population }\end{array}$ & Bureau of Economic Analysis \\
\hline Investment & $\begin{array}{l}\text { Private sector gross investment divided by } \\
\text { its deflator and by population }\end{array}$ & Bureau of Economic Analysis \\
\hline Hours worked & $\begin{array}{l}\text { Product of hours per worker and civilian non-farm } \\
\text { employment divided by population combined with } \\
\text { Francis and Ramey (2002) hours worked series. }\end{array}$ & $\begin{array}{l}\text { Bureau of Economic Analysis } \\
\text { and Francis and Ramey } \\
(2002)\end{array}$ \\
\hline Population & Population above 16 years of age & Bureau of Labor Statistics \\
\hline Federal funds rate & Effective funds rate (annualized) & $\begin{array}{l}\text { Federal Reserve Bank } \\
\text { of St. Louis }\end{array}$ \\
\hline Inflation rate & $\begin{array}{l}\text { Annualized quarter to quarter increase in implicit } \\
\text { GDP deflator }\end{array}$ & Bureau of Economic Analysis \\
\hline Nonborrowed reserves & Non borrowed reserves, final month of the quarter & $\begin{array}{l}\text { Federal Reserve Bank } \\
\text { of St. Louis }\end{array}$ \\
\hline Commodity price inflation & $\begin{array}{l}\text { Annualized quarter to quarter increase in the } \\
\text { KR-CRB spot commodity price index }\end{array}$ & $\begin{array}{l}\text { Commodity Research } \\
\text { Bureau }\end{array}$ \\
\hline Government spending & $\begin{array}{l}\text { Sum of federal current expenditures, gross } \\
\text { investment expenditures, capital transfer payments }\end{array}$ & Bureau of Economic Analysis \\
\hline & $\begin{array}{l}\text { and net purchases of nonproduced assets divided by } \\
\text { its implicit deflator and by population }\end{array}$ & \\
\hline Government revenue & $\begin{array}{l}\text { Total federal receipts divided by government } \\
\text { spending deflator and by population }\end{array}$ & Bureau of Economic Analysis \\
\hline
\end{tabular}




\section{Appendix 2: Deriving the VAR model}

Here we outline how the empirical VAR model can be obtained from a DSGE model. Suppose that labor income and capital income tax rates are stochastic and given by the processes:

$$
\begin{aligned}
\tau_{t}^{n} & =\left(1-\rho_{n}\right) \tau^{n}+\rho_{n} \tau_{t-1}^{n}+\varepsilon_{t}^{n}+\xi_{t, 0}^{n} \\
\tau_{s}^{k} & =\left(1-\rho_{k}\right) \tau^{k}+\rho_{k} \tau_{t-1}^{k}+\varepsilon_{t}^{k}+\xi_{t, 0}^{k}
\end{aligned}
$$

where $\tau^{n}, \tau^{k} \in[0,1)$ are constants that determine the long run unconditional means of the two tax rates. There are two types of innovations to taxes, surprise shocks $\left(\varepsilon_{t}^{n}\right.$ and $\left.\varepsilon_{t}^{k}\right)$ and anticipated tax shocks $\left(\xi_{t, b}^{n}\right.$ and $\left.\xi_{t, b}^{k}\right)$. The latter are pre-announced $b$ quarters in advance and $\xi_{t, 0}^{i}$ denotes the anticipated tax shock to tax rate $i$ which is implemented at date $t$. The innovations to the tax rates are iid with zero mean, $\varepsilon_{t} \sim i i d\left(0, \Omega_{\varepsilon}\right)$ and $\xi_{t} \sim i i d\left(0, \Omega_{\xi}\right)$ where $\varepsilon_{t}=\left[\varepsilon_{t}^{n}, \varepsilon_{t}^{k}\right]^{\prime}$ and $\xi_{t}=\left[\xi_{t}^{n}, \xi_{t}^{k}\right]^{\prime}$. The innovations to the tax rates are allowed to be correlated but we assume that $\varepsilon_{t}$ and $\xi_{t, b}$ are orthogonal.

The solution to a linear rational expectations model can be expressed as:

$$
\begin{aligned}
Z_{s} & =\Lambda_{Z} Z_{s-1}+\Xi_{Z} W_{s} \\
W_{s} & =\Xi_{W} W_{s-1}+\Gamma_{W} \eta_{s} \\
U_{s} & =\Lambda_{U} Z_{s-1}+\Xi_{U} W_{s}
\end{aligned}
$$

where $Z_{s}$ is a vector of endogenous states, $W_{s}$ is a vector of exogenous states, $\eta_{s}$ a vector of innovations including the tax shocks, and $U_{s}$ is a vector of controls. Let $Y_{s}$ be a vector of observables and suppose we wish to estimate how tax innovations affect the dynamics of this vector. This vector is assumed to be a subset (or linear combinations of) of the set of controls and states. The solution for the observables, $Y_{s}$ can be expressed as:

$$
Y_{s}=\Lambda_{Y} Z_{s-1}+\Xi_{Y} W_{s}
$$

It follows from equation (8) that:

$$
Z_{s}=\left(I-\Lambda_{Z} L\right)^{-1} \Xi_{Z} W_{s}
$$

which converges under the condition that the roots of $\Lambda_{Z}$ are strictly less than one in modulus. Under the condition that $\Lambda_{Y}$ is invertible, equations $(11)-(12)$ imply that

$$
Y_{s}=\Lambda_{Y} \Lambda_{Z} \Lambda_{Y}^{-1} Y_{s-1}+\Xi_{Y} W_{s}+\Lambda_{Y}\left(\Xi_{Z}-\Lambda_{Z} \Lambda_{Y}^{-1} \Xi_{Y}\right) W_{s-1}
$$


Assume that $\operatorname{dim}(Y)=\operatorname{dim}(Z)$ so that there are as many innovations as measurement variables. From equation (9) we have that:

$$
W_{s}=\Gamma_{W} \eta_{s}+\Xi_{W} \Gamma_{W} \eta_{s-1}+\Xi_{W}^{2} \Gamma_{W} \eta_{s-2}+. .
$$

which converges given that $\Xi_{W}$ has roots inside the unit circle. Inserting this into equation (??) we find that:

$$
\begin{aligned}
Y_{s} & =A Y_{s-1}+\sum_{i=0}^{\infty} B_{i} \eta_{s-i} \\
A & =\Lambda_{Y} \Lambda_{Z} \Lambda_{Y}^{-1}, B_{0}=\Xi_{Y} \Gamma_{W} \\
B_{i} & =\left[\Xi_{Y} \Xi_{W}+\Lambda_{Y}\left(\Xi_{Z}-\Lambda_{Z} \Lambda_{Y}^{-1} \Xi_{Y}\right)\right] \Xi_{W}^{i-1} \Gamma_{W} \text { for } i \geq 1
\end{aligned}
$$

$\Xi_{W}$ is a dampening matrix given as:

$$
\Xi_{W}=\left[\begin{array}{ccc}
R & I_{2} & 0_{2,2(b-1)} \\
0_{2(b-1), 2} & 0_{2(b-1), 2} & I_{2(b-1)} \\
0_{2,2} & 0_{2,2} & 0_{2,2(b-1)}
\end{array}\right], R=\left[\begin{array}{cc}
\rho_{n} & 0 \\
0 & \rho_{k}
\end{array}\right]
$$

Therefore, the roots of $\Xi_{W}$ are less than or equal to one under the conditions that $\left|\rho^{n}\right|<1$ and $\left|\rho^{k}\right|<1$. Finally, in order to derive equation (??) note that, $\eta_{s-j}=\left[\begin{array}{llll}\varepsilon_{s-j}^{n} & \varepsilon_{s-j}^{k} & \xi_{s-j, b-j}^{n} & \xi_{s, b-j}^{k}\end{array}\right]^{\prime}$ for $j<b$ while $\eta_{s-j}=\left[\begin{array}{llll}\varepsilon_{s-j}^{n} & \varepsilon_{s-j}^{k} & \xi_{s+b-j, 0}^{n} & \xi_{s+b-j, 0}^{k}\end{array}\right]^{\prime}$. Thus, the process for the observables can be expressed as:

$$
Y_{s}=A Y_{s-1}+\sum_{i=0}^{\infty} B_{i}^{\varepsilon} \eta_{s-i}^{u}+\sum_{i=0}^{\infty} B_{i+b}^{\xi} \eta_{s-i}^{a}+\sum_{i=0}^{b-1} B_{i}^{\xi} \eta_{s-i}^{\xi}
$$

where:

$$
\begin{aligned}
\eta_{s-i}^{\varepsilon} & =\left[\begin{array}{ll}
\varepsilon_{s}^{n} & \varepsilon_{s}^{k}
\end{array}\right]^{\prime}, \eta_{s-i}^{a}=\left[\begin{array}{cc}
\xi_{s-i, 0}^{n} & \xi_{s-i, 0}^{k}
\end{array}\right]^{\prime}, \eta_{s-i}^{\xi}=\left[\begin{array}{cc}
1 & 0 \\
\xi_{s-j, b-j}^{n} & \xi_{s, b-j}^{k}
\end{array}\right]^{\prime} \\
B_{i}^{\varepsilon} & =B_{i} H_{\varepsilon}, B_{i}^{\eta}=B_{i} H_{\eta}, H_{\varepsilon}=\left[\begin{array}{ll}
0 & 0 \\
0 & 1 \\
0 & 0 \\
0 & 0
\end{array}\right], H_{\xi}=\left[\begin{array}{ll}
0 & 0 \\
1 & 0 \\
0 & 1
\end{array}\right]
\end{aligned}
$$


Table 1: Tests of Exogeneity of Tax Liability Changes

\begin{tabular}{cccc}
\hline \hline & \multicolumn{3}{c}{ All "exogenous" tax changes } \\
\cline { 2 - 4 } Test statistic & 10.77 & 3.545 & Anticipated \\
P-value & 0.952 & 0.999 & 17.97 \\
& Long run growth motivated tax changes \\
\cline { 2 - 4 } & All & Surprise & Anticipated \\
Test statistic & 8.051 & 6.255 & 5.838 \\
P-value & 0.992 & 0.999 & 0.999 \\
\hline \multirow{2}{*}{ Test statistic } & 19.61 & 2.266 & Anticipated \\
\cline { 2 - 4 } P-value & 0.482 & 0.999 & 0.095 \\
\hline \hline
\end{tabular}

Notes: The table reports the outcomes of likelihood ratio tests of the hypothesis that four lags of the vector $X_{t}$ have no predictive power for tax liability changes dated by their announcements. The models are specified as ordered probits and "P-value" is the probability of the test statistic under the null of no predictability. The vector $X_{t}$ includes linearly detrended logarithms of output, investment, consumption, hours worked (all in per adult terms) and real wages. 


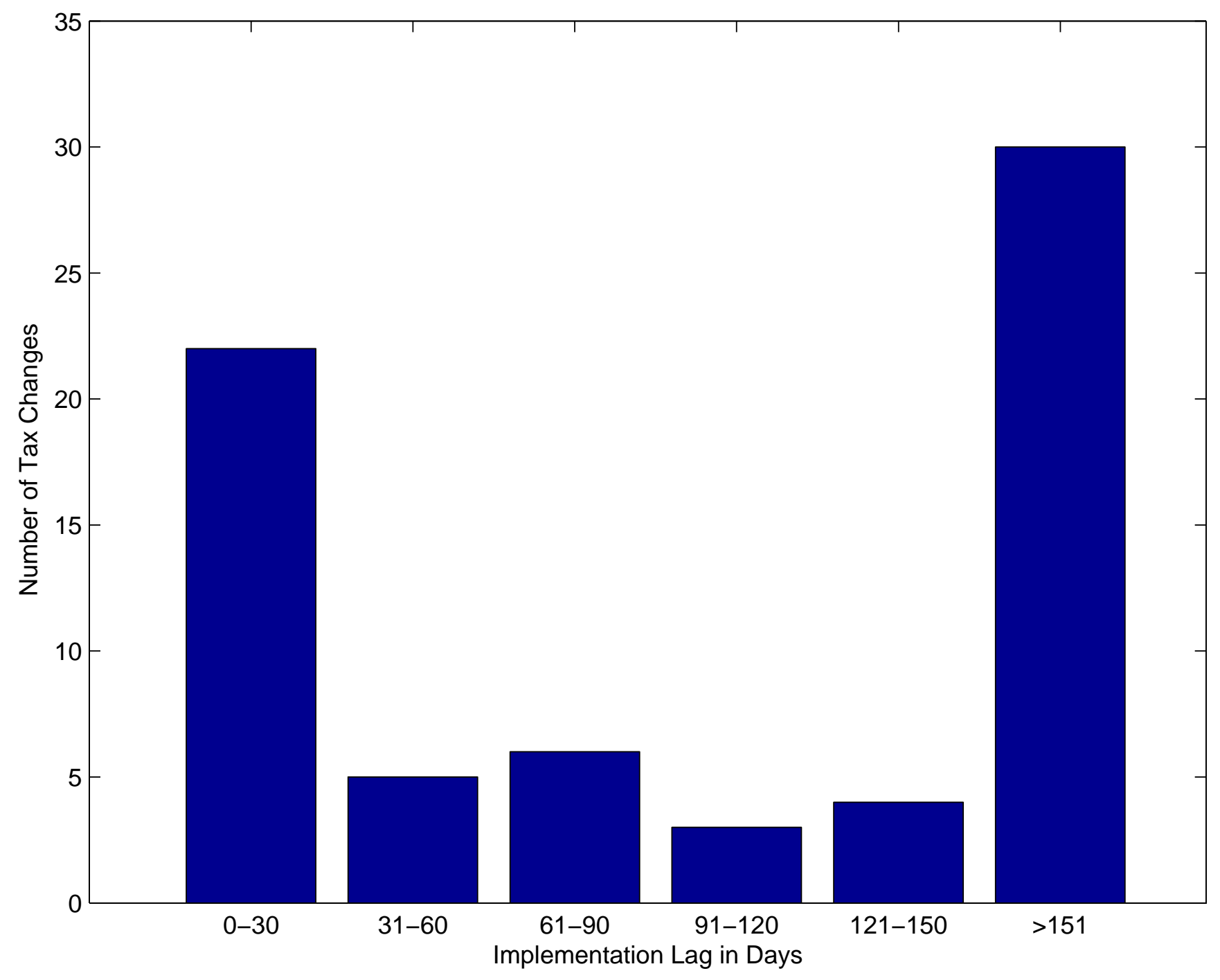

Figure 1: The Distribution of Implementation Lags Across Tax Liability Changes 


\section{Unanticipated Tax Liability Changes}
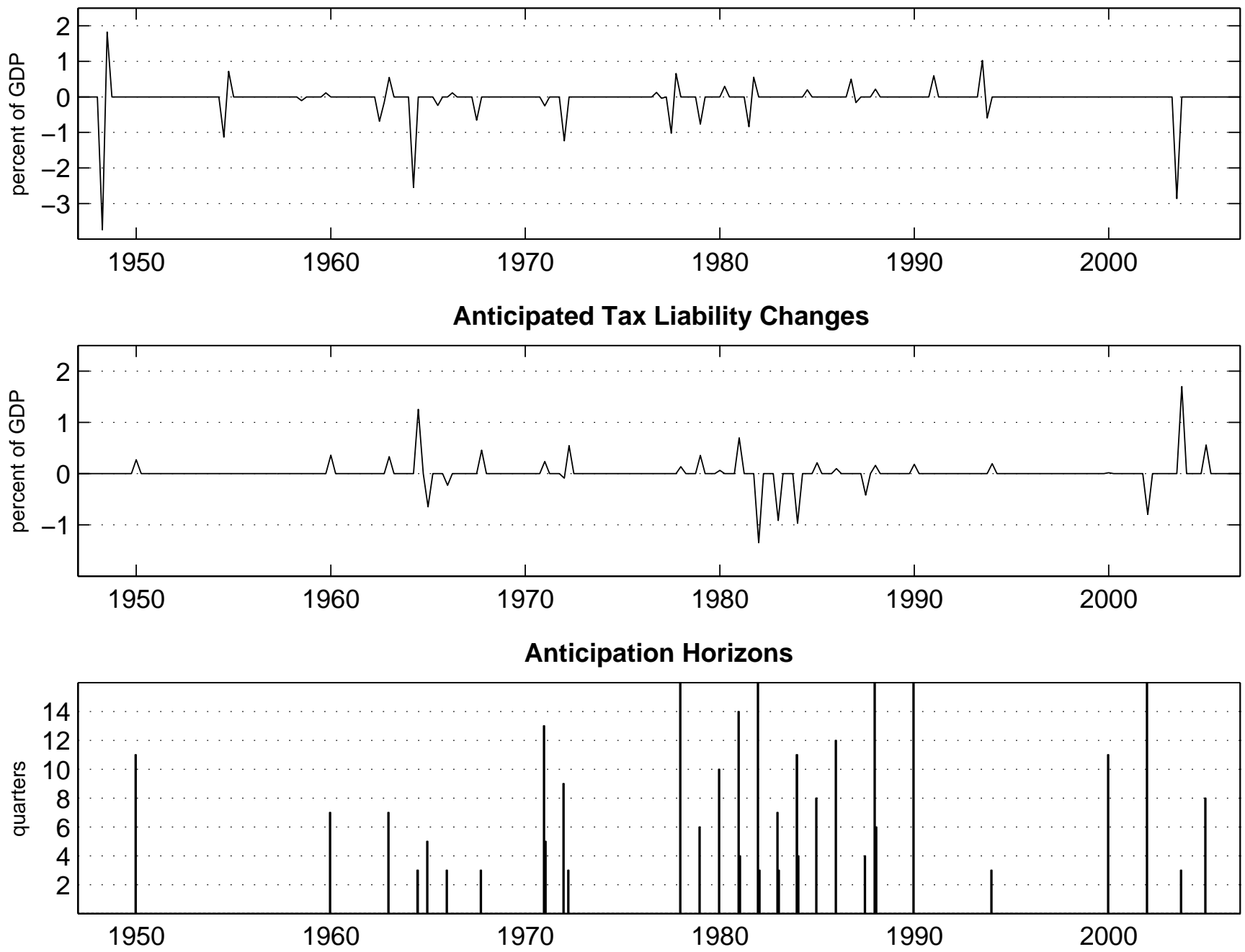

Figure 2: Tax Liability Changes as Percent of Current Price GDP (the top panel illustrates unanticipated tax changes, the middle panel illustrates anticipated tax changes dated at the implementation date, the lower panel shows the implementation lag in quarters of the anticipated tax changes censored at 16 quarters) 

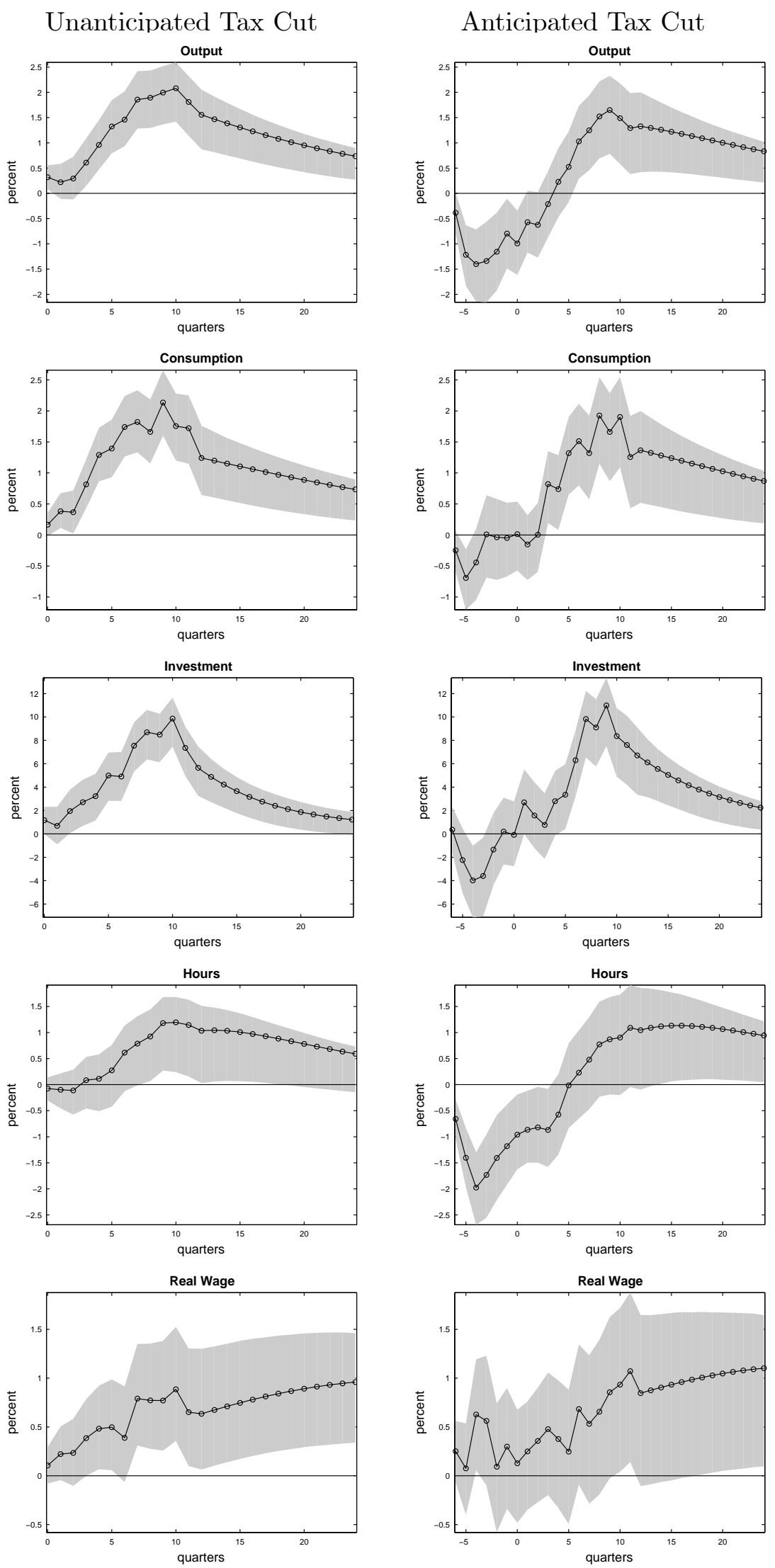

Figure 3: The Impact of a 1 percent Tax Liability Cut (lines with circles indicates point estimates, grey areas are 68 percent bootstrapped confidence intervals) 


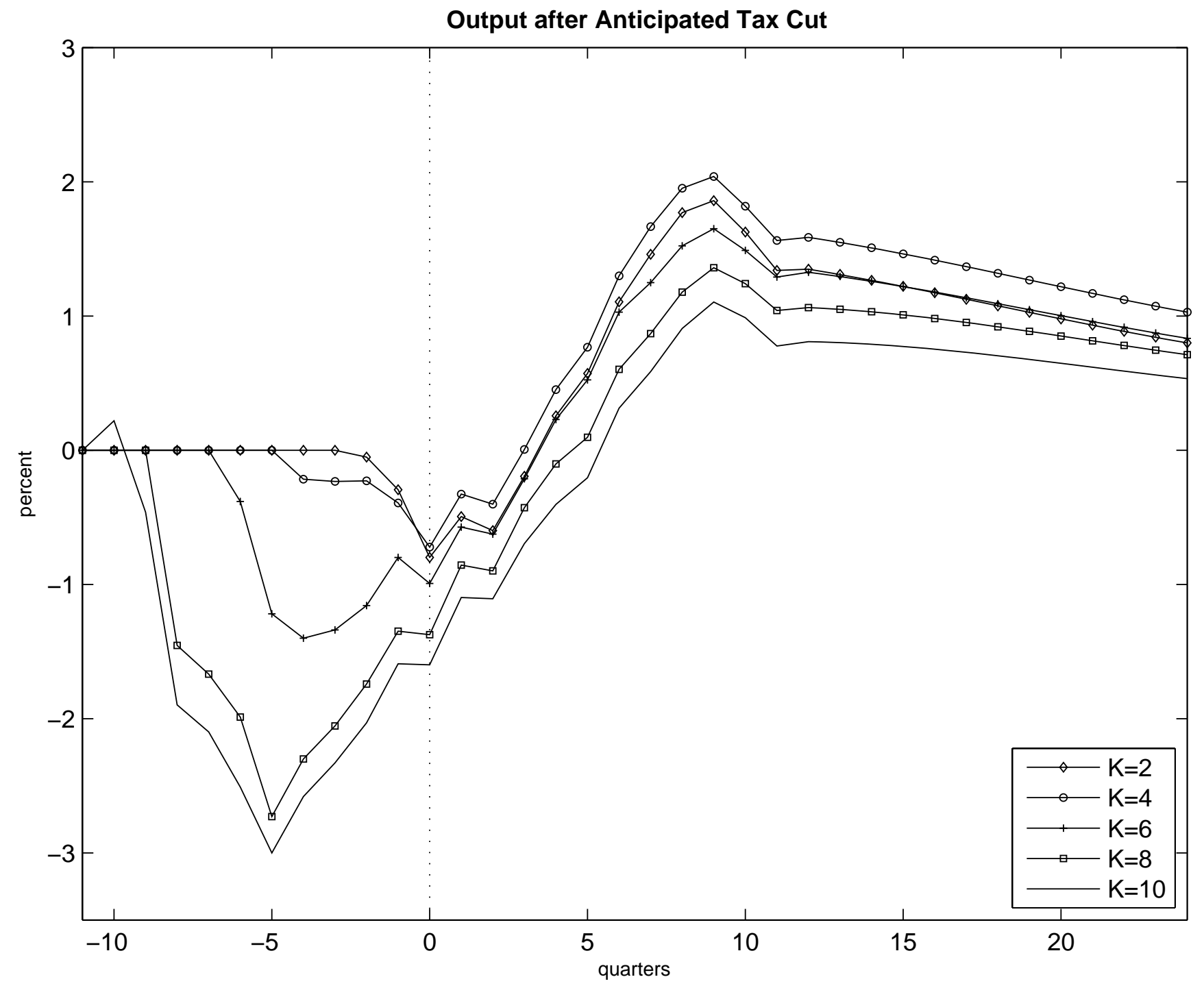

Figure 4: The Impact on Output of a 1 Percent Anticipated Tax Cut for Alternative Anticipation Horizons 
Leads of Unanticipated Tax Shocks
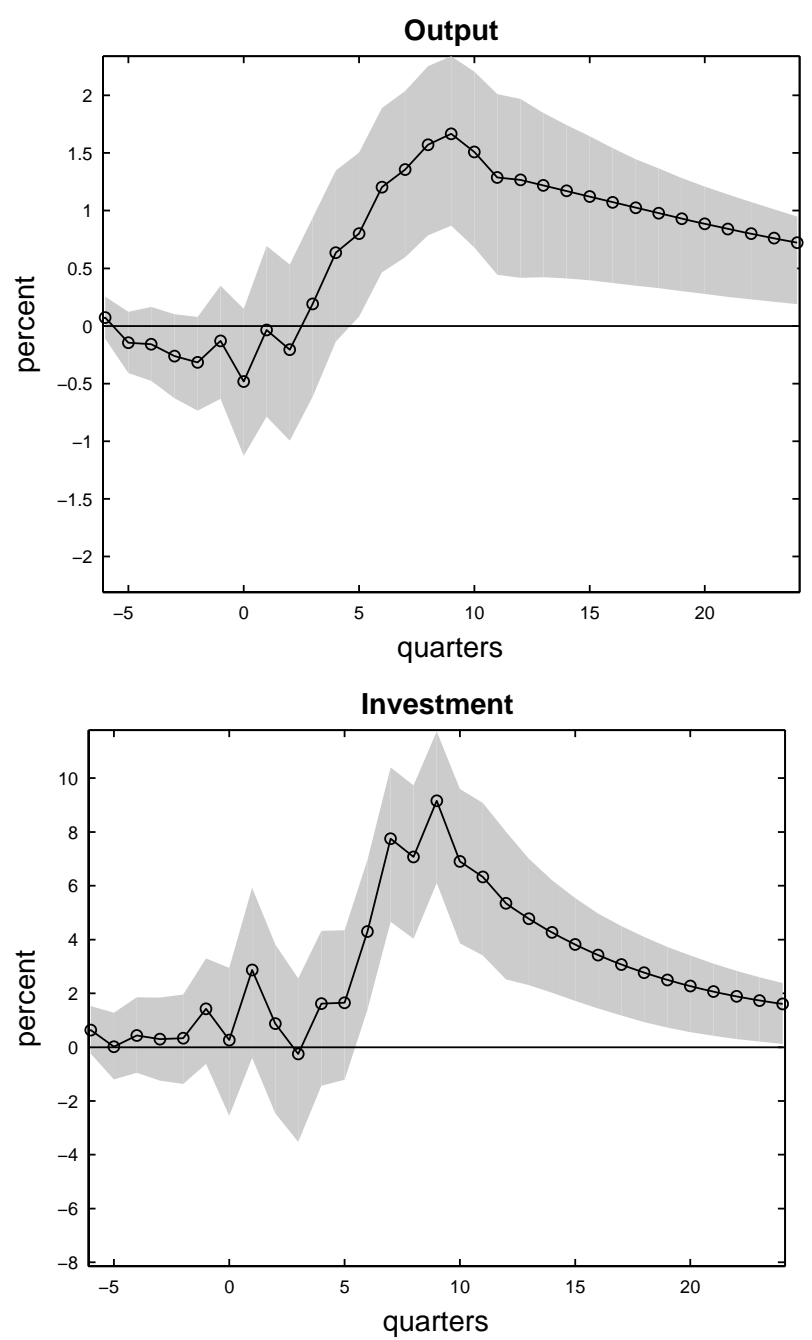

Anticipated Tax Shocks
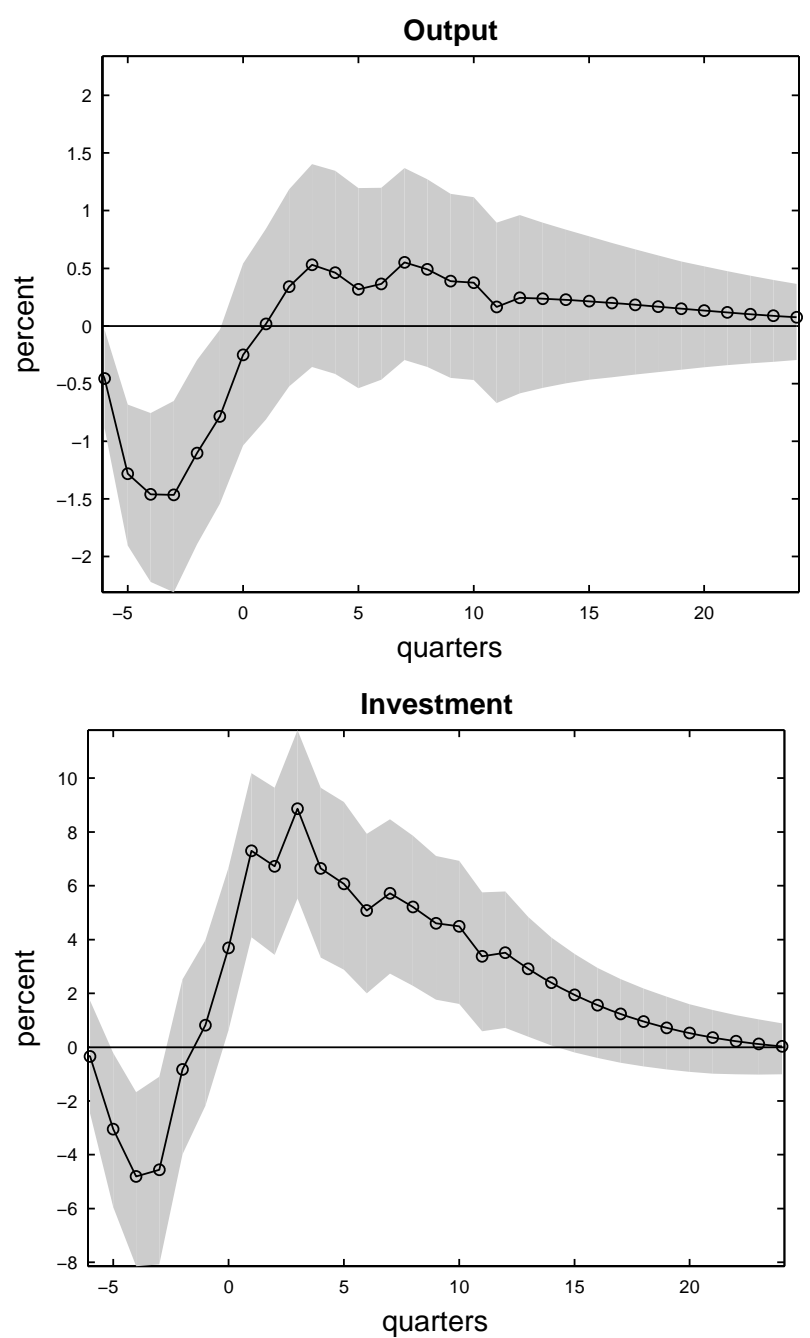

Figure 5: The Impact of a 1 Percent Tax Cut Allowing for Anticipation of Surprise Tax Shocks (the impulse responses are estimated from equation (3)) 
Unanticipated Tax Cut
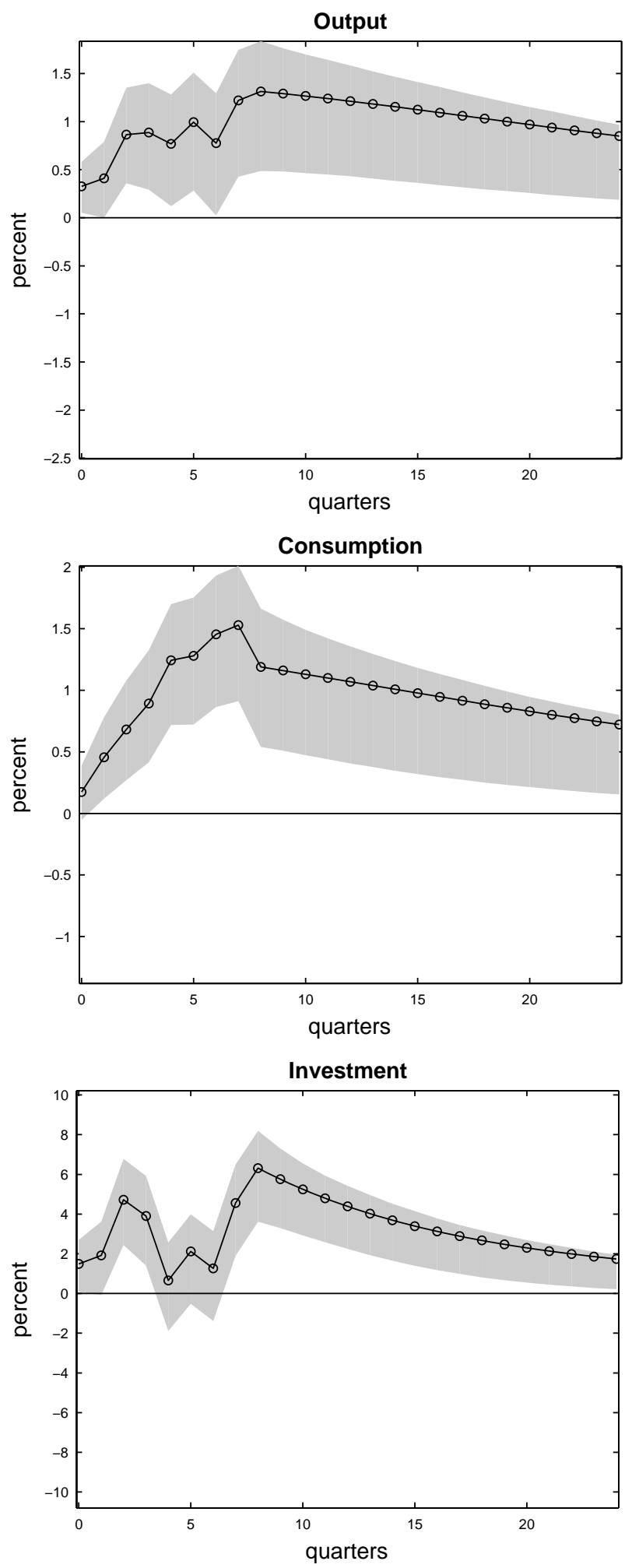

Anticipated Tax Cut
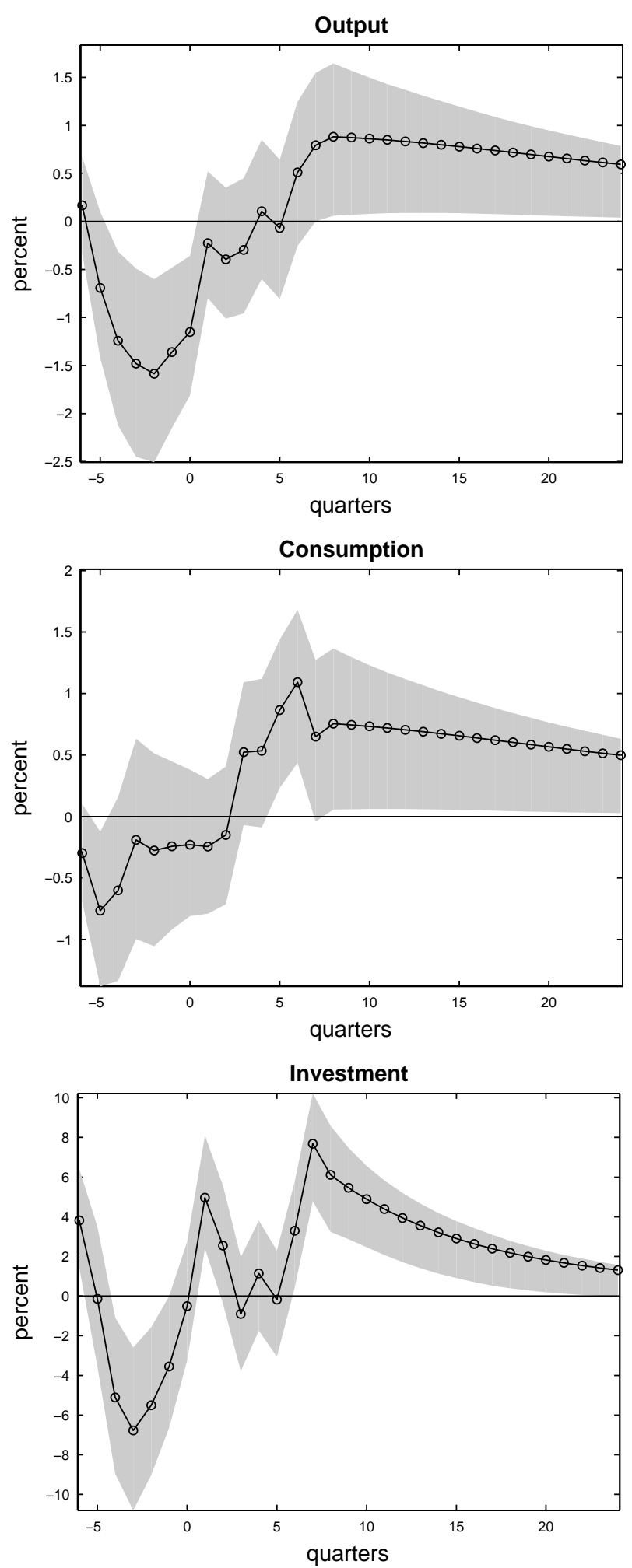

Figure 6: The Impact of a 1 Percent Tax Cut Introduced for Long Run Growth Reasons 
Unanticipated Tax Cut
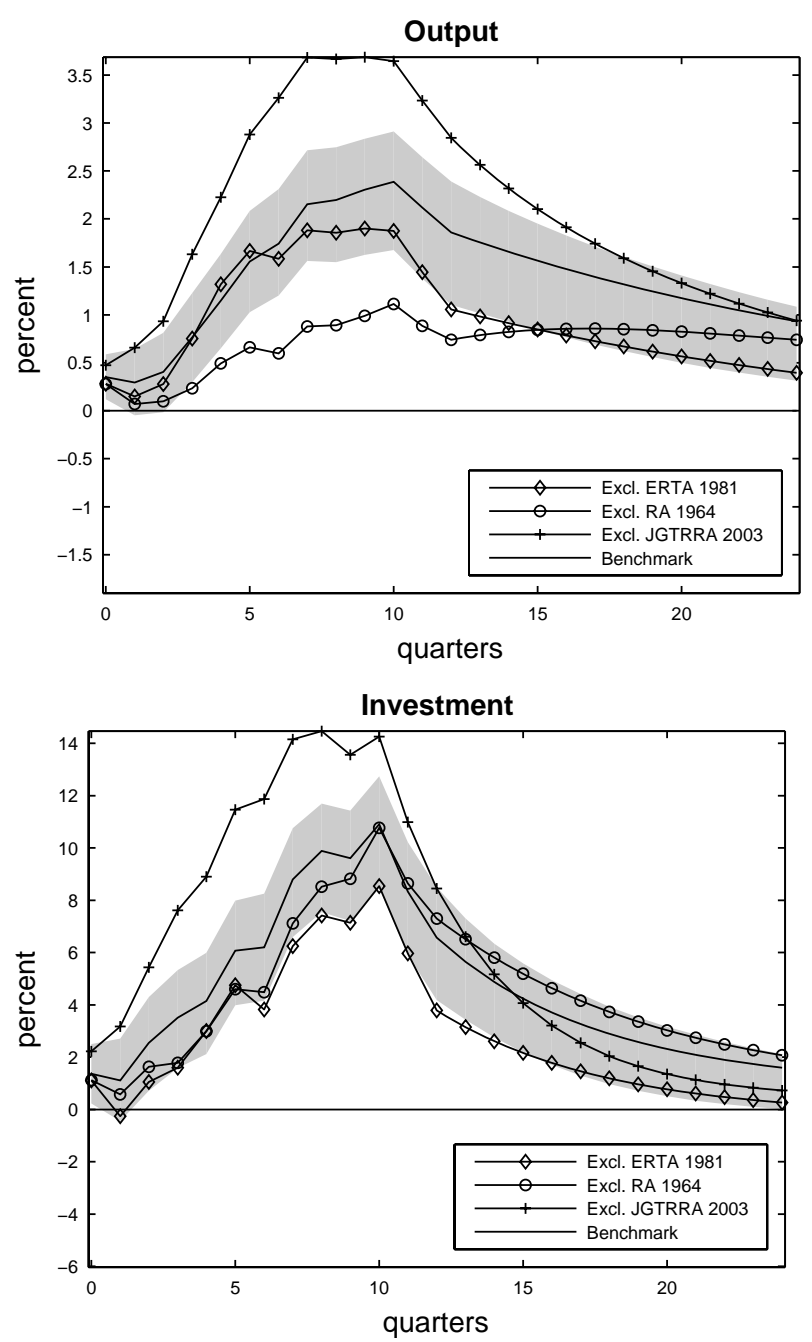

Real Wage

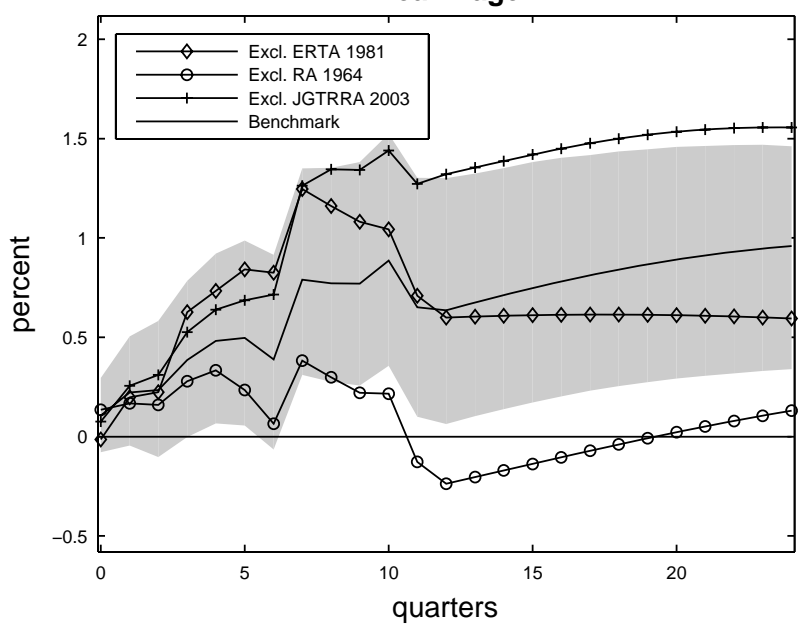

Anticipated Tax Cut
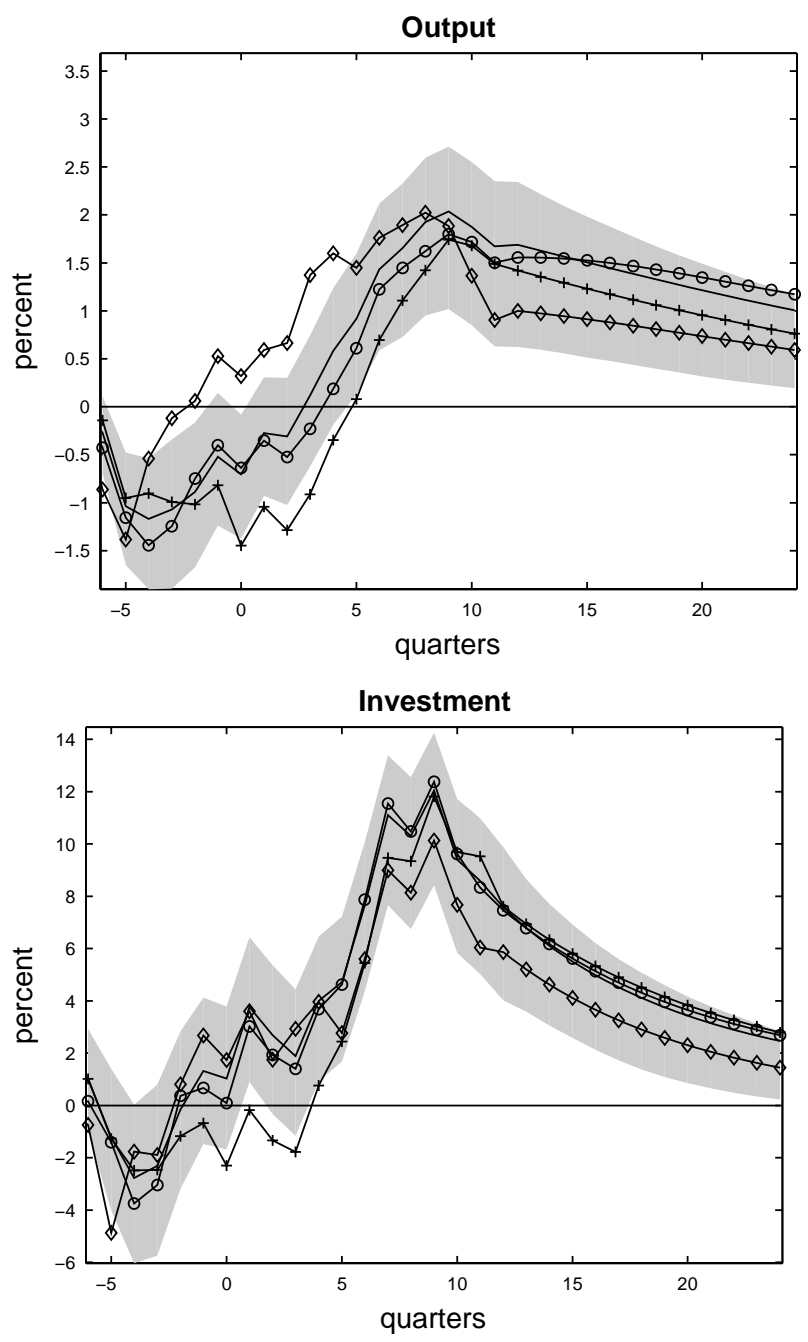

Real Wage

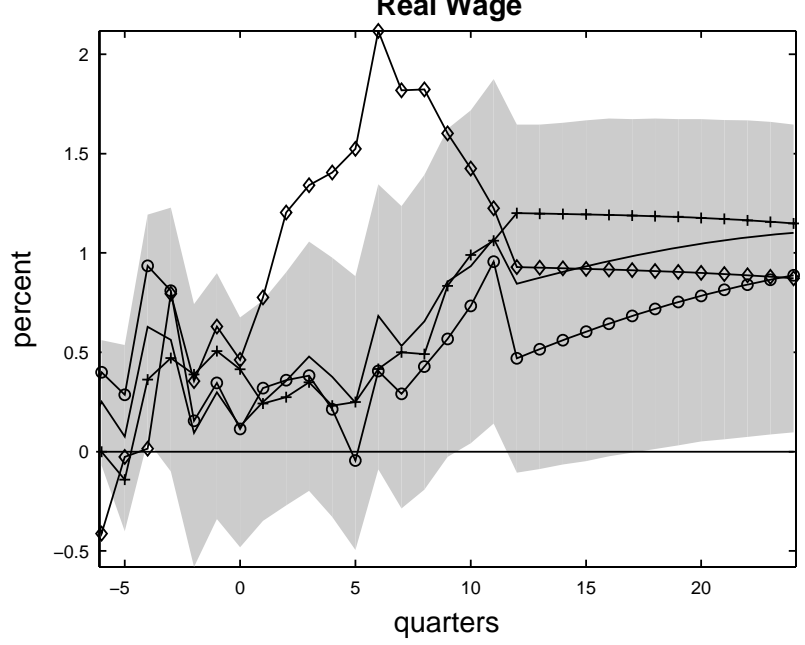

Figure 7: Stability of Estimates Across Tax Acts

(the diagrams show the impact of a 1 percent tax liability cut when eliminating RA 1964,

ERTA 1981 or JGTRRA 2003 from the sample, respectively) 
Unanticipated Tax Cut
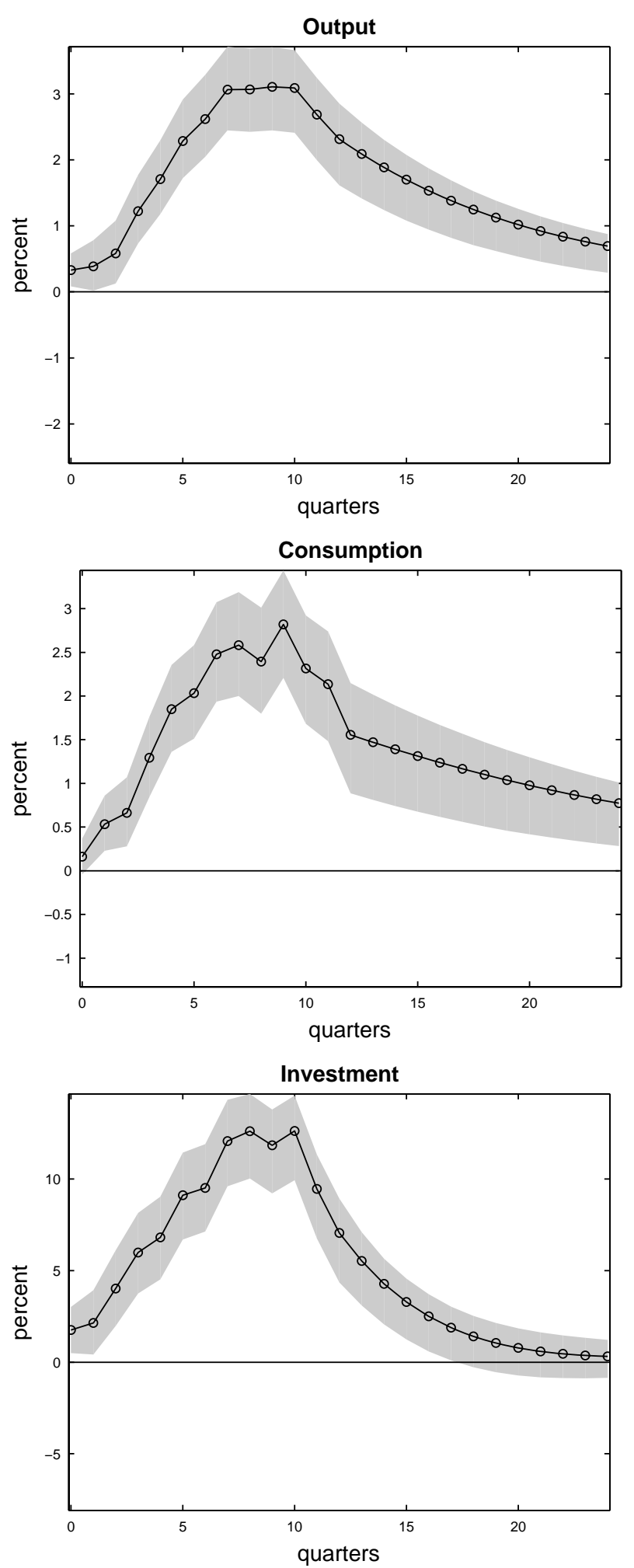

Anticipated Tax Cut
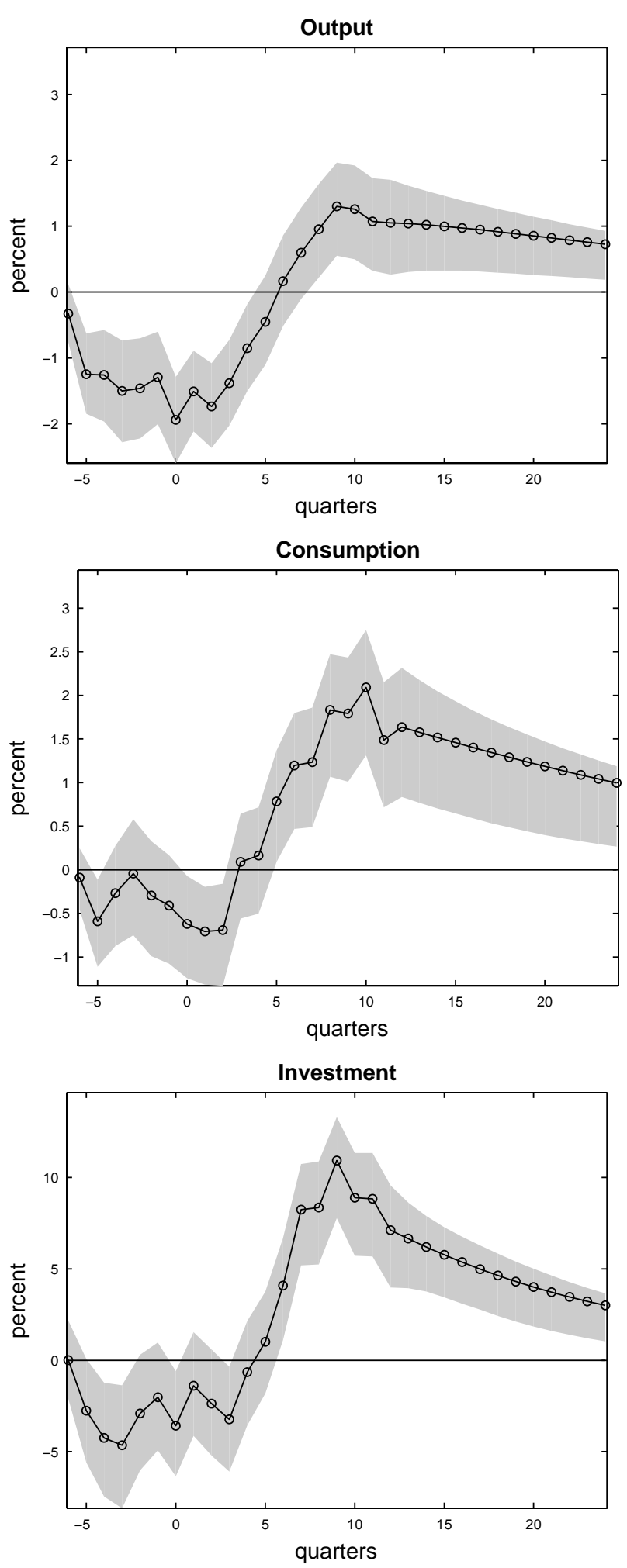

Figure 8: The Impact of a 1 Percent Permanent Tax Cut 
Unanticipated Tax Cut
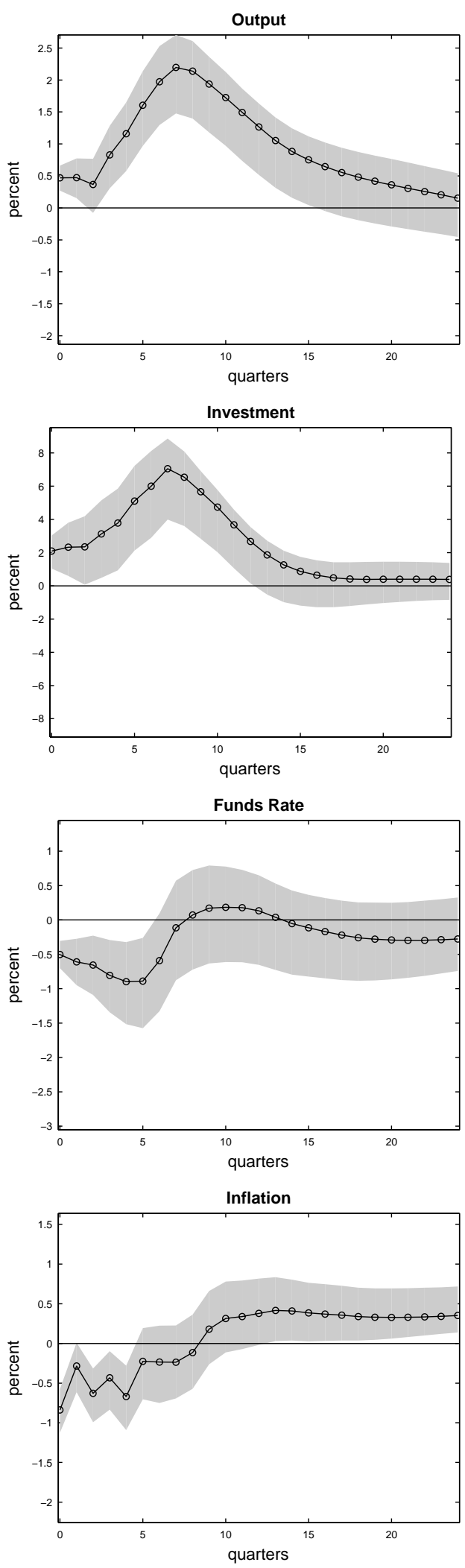

Anticipated Tax Cut
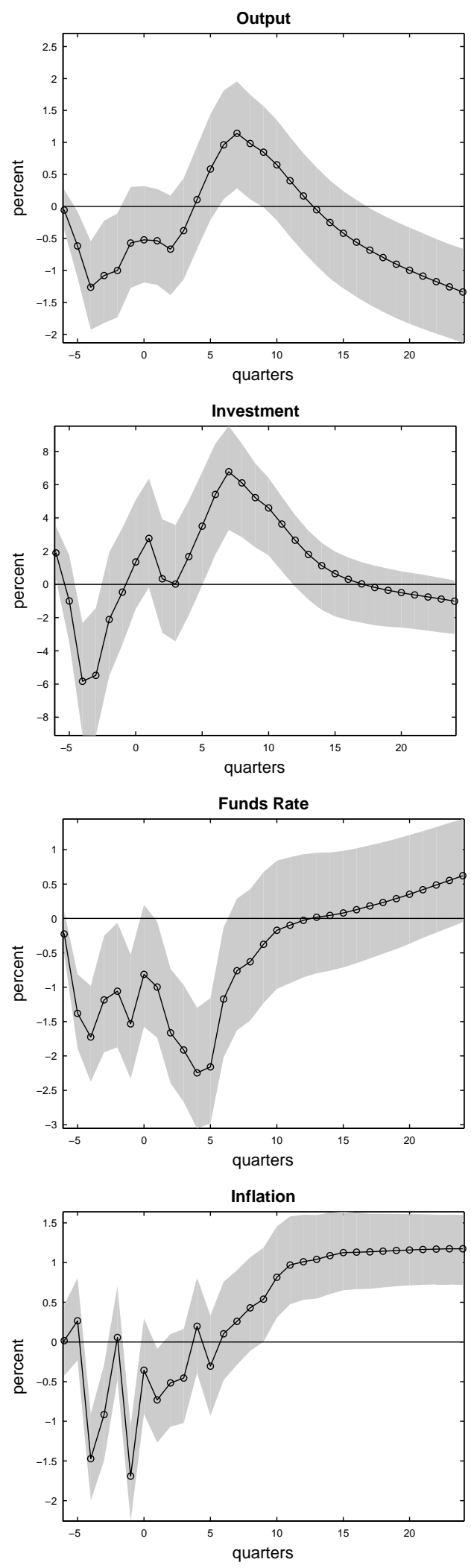

Figure 9: The Impact of a 1 Percent Tax Cut Controlling for Monetary Variables (the figure shows the estimates from equation 4) 
Unanticipated Tax Cut
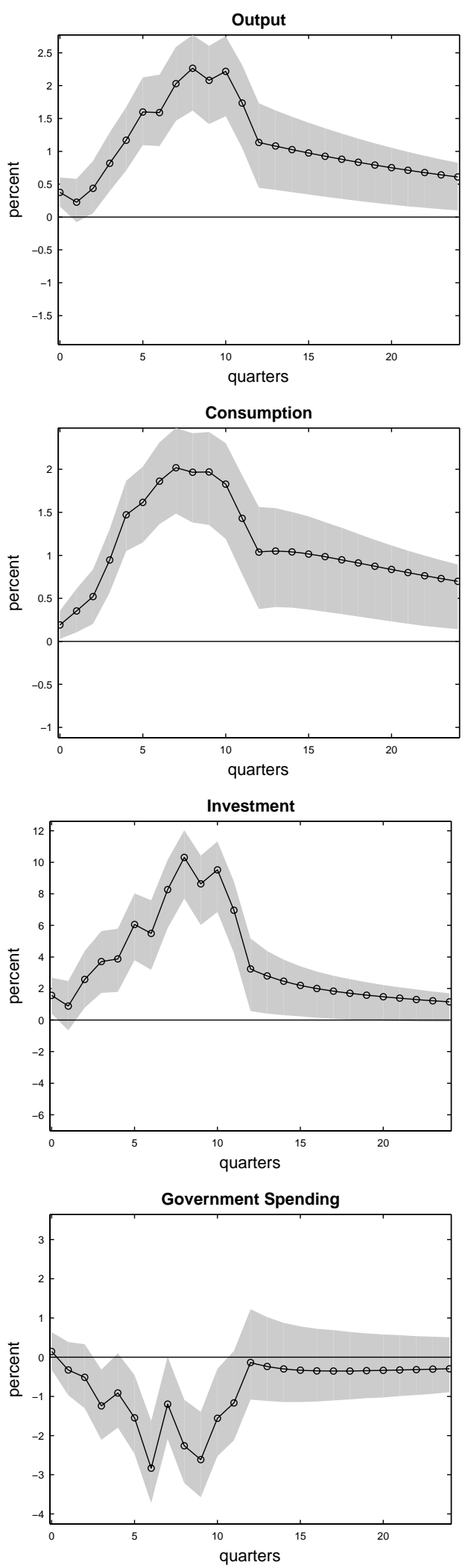

Anticipated Tax Cut
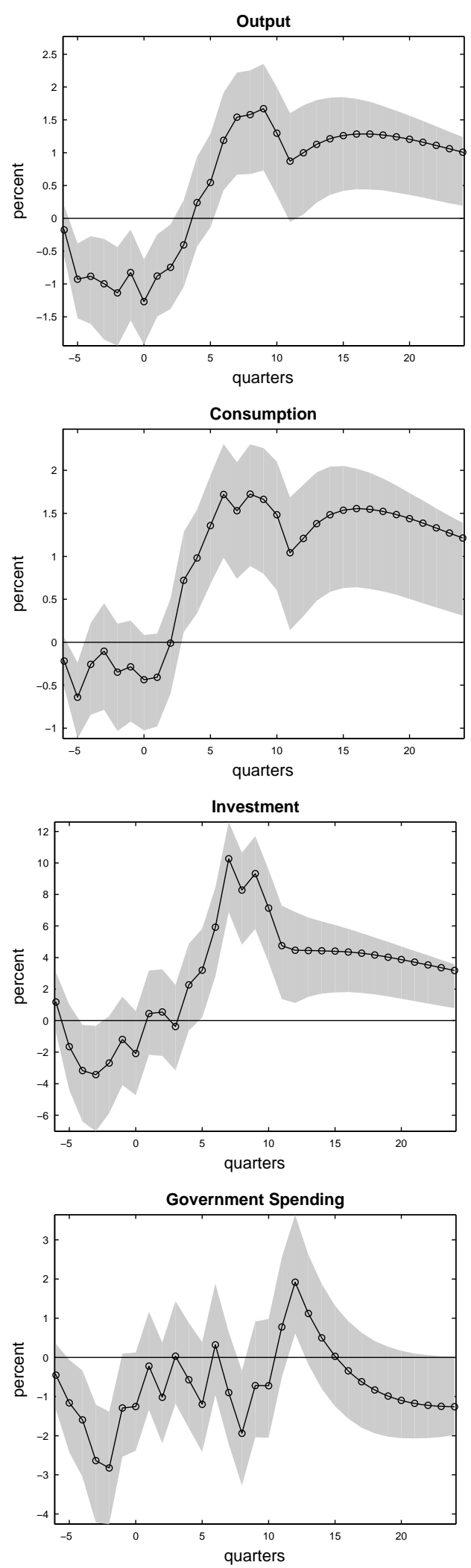

Figure 10: The Impact of a 1 Percent Tax Cut Controlling for Government Spending and Government Revenue (the figure shows the estimates from equation 5) 

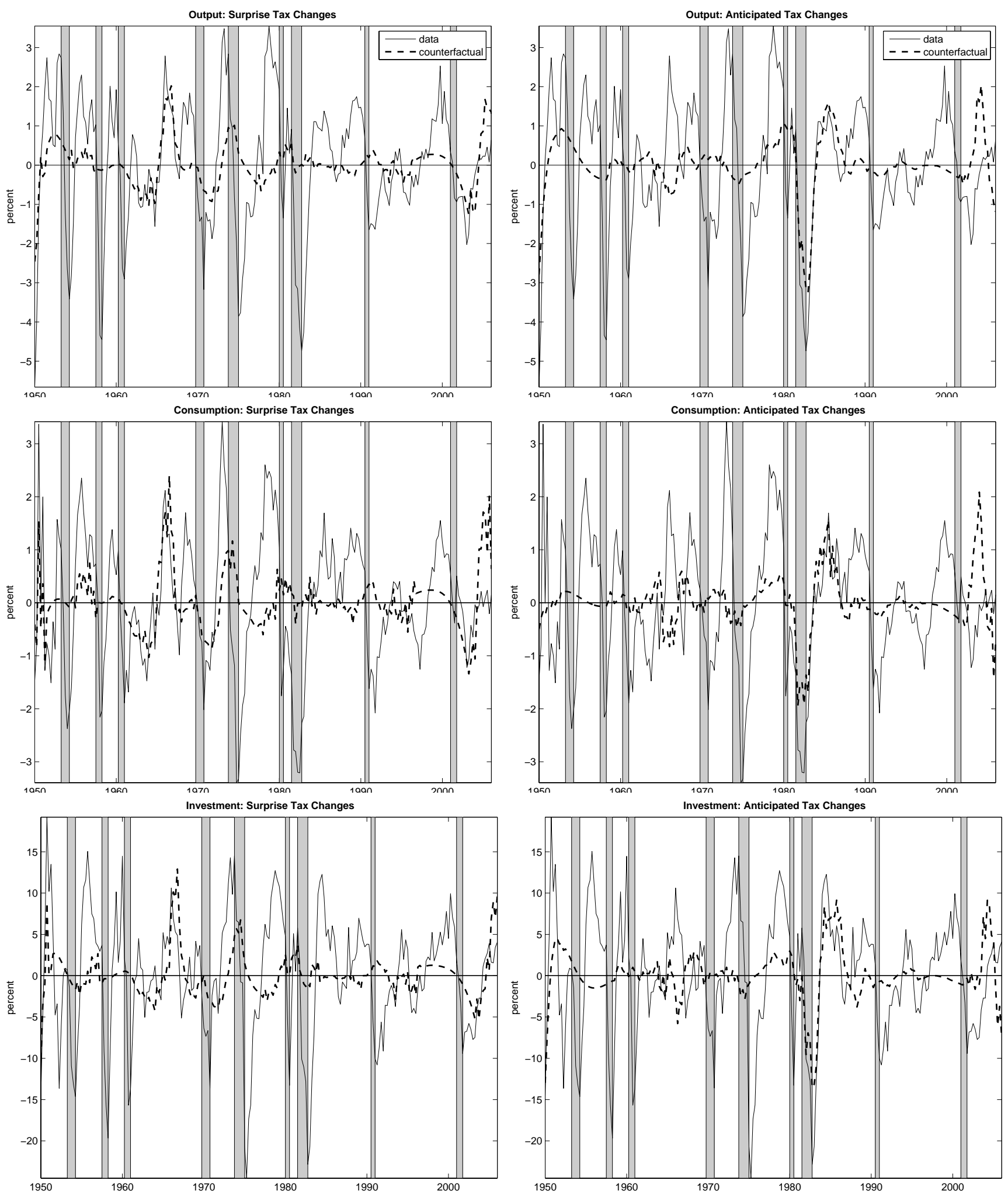

Figure 11: Counterfactual Analysis of US Business Cycles

(the figure illustrates HP-filtered actual and simulated output, consumption, and investment. In panel A, equation 2 is simulated setting all shocks by the surprise tax shock equal to zero; In panel B, equation 2 is simulated setting all but the anticipated tax shock equal to zero. Shaded areas indicate recessions according to the NBER datings) 
Panel C: All tax shocks
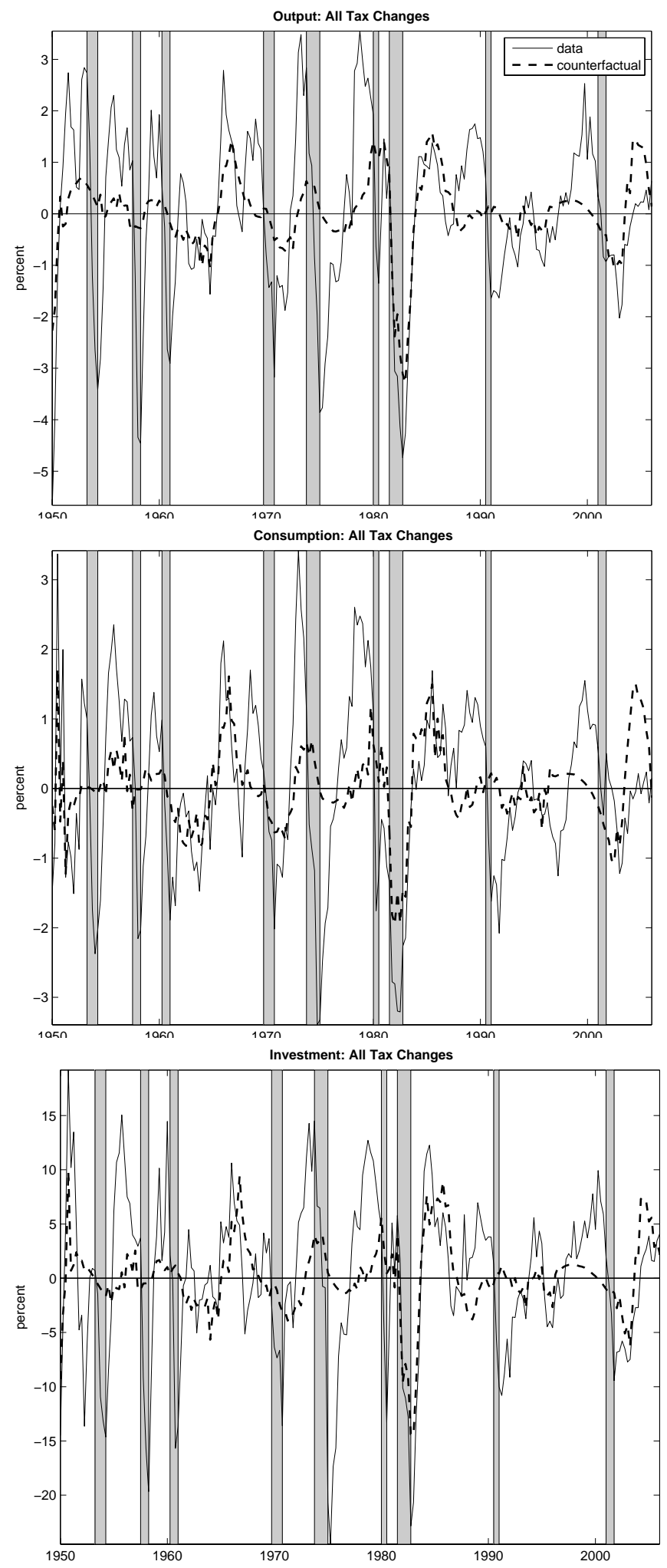

Figure 11, continued

(panel C illustrates the case where all shocks apart from the tax shocks are set equal to zero) 

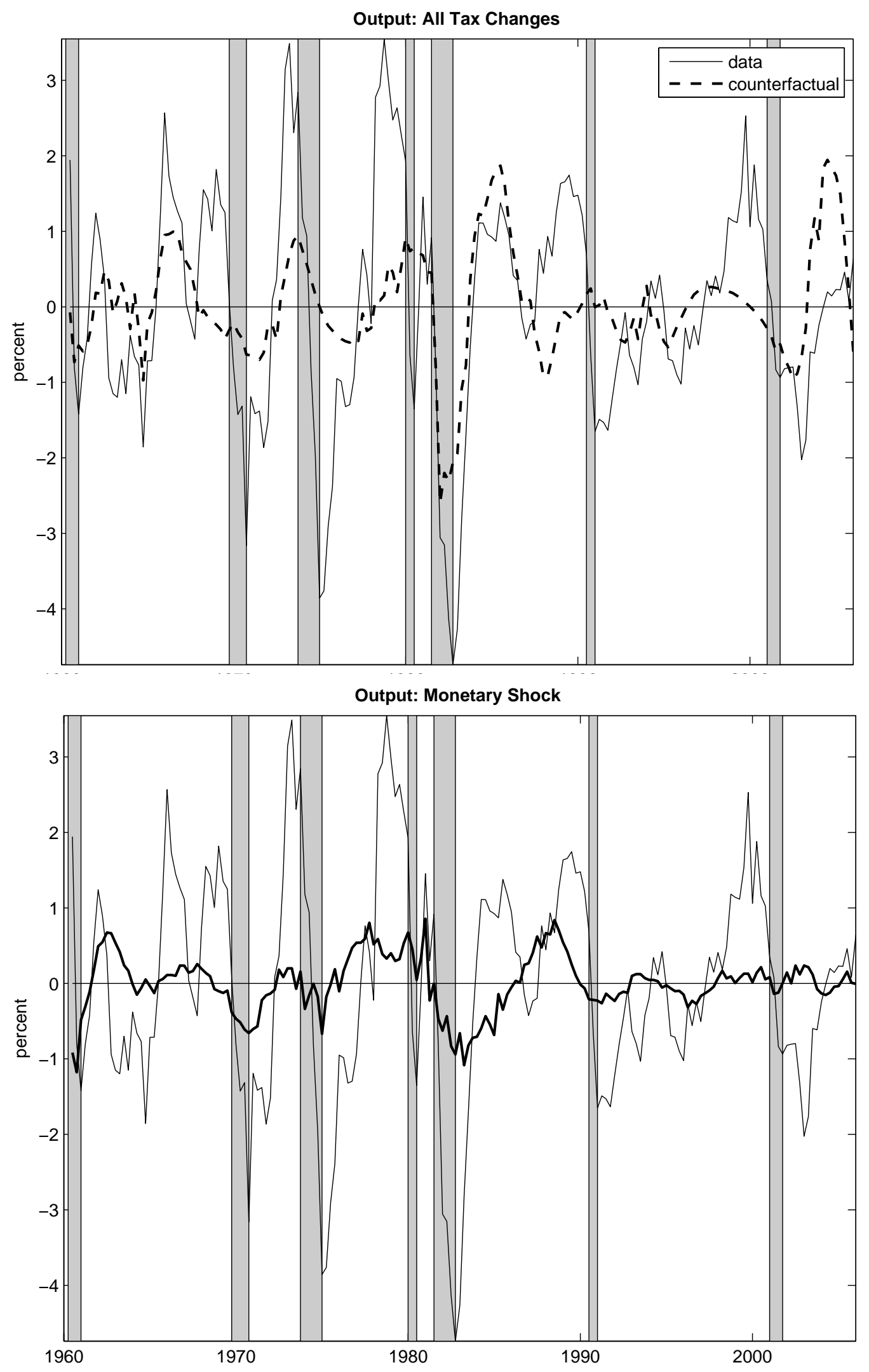

Figure 12: Counterfactual Output from the Monetary VAR

(the figure illustrates HP filtered actual and simulated output series; the top figure illustrates output when simulating the VAR in equation 4 allowing only for tax shocks; the bottom figure illustrates output wen simulating the VAR in equation 4 allowing only for monetary policy shocks) 